\title{
Numerical Simulation of the Performance of Applying Different Nanofluids in a Tube with a $90^{\circ}$ Bend at the Center of the Tube
}

\author{
Dinesh Kumar, ${ }^{1}$ Gurpreet Singh Sokhal, ${ }^{1}$ Nima Khalilpoor $\mathbb{D}^{2},{ }^{2}$ AlibekIssakhov, ${ }^{3}$ \\ and Babak Mosavati ${ }^{4}$ \\ ${ }^{1}$ Mechanical Engineering Department, Chandigarh University, Gharuan, Mohali, Punjab, India \\ ${ }^{2}$ Department of Energy Engineering, Graduate School of the Environment and Energy, Science and Research Branch, \\ Islamic Azad University, Tehran, Iran \\ ${ }^{3}$ Faculty of Mechanics and Mathematics, Department of Mathematical and Computer Modelling, Al-Farabi Kazakh \\ National University, Almaty, Kazakhstan \\ ${ }^{4}$ Department of Mechanical and Ocean Engineering, Florida Atlantic University, Boca Raton, FL 33431, USA
}

Correspondence should be addressed to Nima Khalilpoor; nimakhalilpoor@gmail.com

Received 14 April 2021; Revised 14 July 2021; Accepted 28 July 2021; Published 6 September 2021

Academic Editor: JOSE M. MATA PADILLA

Copyright (C) 2021 Dinesh Kumar et al. This is an open access article distributed under the Creative Commons Attribution License, which permits unrestricted use, distribution, and reproduction in any medium, provided the original work is properly cited.

\begin{abstract}
This research manuscript addresses the study of the performance of a flat tube having a $90^{\circ}$ bend under the flow of three different nanofluids such as copper oxide, multiwalled carbon nanotubes, and aluminum oxide/water nanofluids at different inlet fluid temperatures and Reynolds numbers. The performance of the flat tube is analyzed under the Reynolds number between 5000 and 11000 and a fluid inlet temperature range of $35^{\circ} \mathrm{C}-50^{\circ} \mathrm{C}$. The results obtained in this study show that the heat transfer coefficient increases with the increase in volume concentration as well as Reynolds number. The maximum heat transfer coefficient is obtained using multiwalled carbon nanotubes followed by copper oxide and then aluminum oxide. This study also illustrates that the friction factor increases with the increase in volume concentration and decrease in Reynolds number. The results of the numerical study have been validated with the help of an experimental study. The study has proved that the use of nanofluids instead of the conventional fluid can lead to reducing the size of the tube for the same amount of heat transfer which can prove the reduction of the size in heat transfer equipment. Furthermore, it is also observed in this study that the presence of the $90^{\circ}$ bend in the flat tube improved the heat transfer performance due to the increased turbulence at the bent section of the tube.
\end{abstract}

\section{Introduction}

Heat transfer enhancement has been a topic for various thermal application over the last decades. Very high thermal performance criterion has been obtained for various applications of heat and mass transfer using different methods and configurations [1]. The conventional fluids like water and ethylene glycol have low thermal conductivity which results in lower thermal performance [2]. Maxwell provided the research community with the concept of using fluids having low thermal conductivity dispersed with small solid particles with higher thermal conductivity. Maxwell also developed a correlation for determining the thermal conductivity of the fluid mixture with the help of properties of both fluid and solid particles. But, it was only after the introduction of nanofluids by Pak and Choi in 1995 that nanofluids became very popular due to their potential of replacing various conventional cooling fluids having low conductivity [3, 4]. Cacua et al. [5] experimentally investigated the thermal conductivity of aqueous $\mathrm{TiO}_{2}$ nanofluids and concluded that the thermal conductivity of nanofluid is higher than that of water or base fluid. Thermal conductivity was also found to increase with an increase in temperature. Nanoparticles can be utilized in various heat transfer applications due to 
their better thermal properties as compared with millimeter and micrometer particles. Nanofluids are used in various fields such as defense, automobile, biomedical industry, aerospace, electronic devices, and nuclear reactor. Application of nanofluid types of nanostructure in solar energy was studied in previous studies [6,7]. Ahmadi et al. [8, 9] studied the application of a nanotechnology in renewable energy and some technologies such as solar cell, biofuel, and hydrogen production. Ramezanizadeh et al. [10] reviewed the application of nanofluids in a thermosiphon. They investigated various works on the effects of several nanofluids on the thermal performance of thermosyphons and concluded that the use of nanofluids instead of base fluid leads to the improved performance of thermosyphons due to the improved thermal conductivity and the effect of nanoparticles on boiling heat transfer.

Various thermophysical properties which affect the heat transfer performance of nanofluids are effective density, effective viscosity, effective thermal conductivity, and effective specific heat. The general trend shows that the addition of nanoparticles to conventional fluid causes an increase in density and thermal conductivity of fluids which are the driving factor behind the enhancement of the heat transfer performance. On the other hand, viscosity of fluid also increases causing a loss in performance of nanofluids. Many studies have been conducted in the past to study and validate various thermodynamic parameters of nanofluids. Sahoo et al. [11] investigated the effects of temperature and nanoparticle concentrations on the dynamic viscosity of $\mathrm{Al}_{2} \mathrm{O}_{3}$ $\mathrm{CuO}-\mathrm{TiO}_{2}$ ternary hybrid nanofluid. It has been presented in this study that the maximum enhancement of the dynamic viscosity of $17.25 \%$ and $55.41 \%$ has been observed for $0.1 \%$ vol. concentration compared with water-based $\mathrm{Al}_{2}$ $\mathrm{O}_{3}-\mathrm{CuO}$ and $\mathrm{Al}_{2} \mathrm{O}_{3}-\mathrm{TiO}_{2}$ hybrid nanofluids, respectively, at a temperature of $45^{\circ} \mathrm{C}$. The investigation conducted by Abdollahi et al. [12] shows that the increase in the temperature causes the value of dynamic viscosity to decrease significantly. Based on outcomes of this study correlation was proposed dynamic viscosity based on the mass fraction of $\mathrm{CuO}$ and temperature. Murshed et al. [13] studied the thermophysical properties such as thermal conductivity of nonaqueous silicon oil and ethylene glycol-based $\mathrm{TiO}_{2}$ nanofluids. It was observed that the viscosity of nanofluid enhances upon the addition of the nanoparticle but it decreases nonlinearly with the increase in temperature. Nikulin et al. [14] also reported the nonlinear trend of viscosity of nanofluid versus temperatures in their study. Duangthongsuk et al. [15] carried out some experiments to study the dynamic viscosity and thermal conductivity of nanofluids. The results of this study show that the viscosity and thermal conductivity of nanofluids increase with the increase in volume concentration of nanoparticles. This study also shows that the thermal conductivity of nanofluid increases with the increase in temperature but viscosity decreases with the increase in temperature. Khedkar et al. [16] investigated the effect of $\mathrm{CuO}$ nanoparticles on the thermal conductivity of fluids like water and monoethylene glycol. They also found that thermal conductivity of fluids improved as the sonication time was increased. Godson et al. [17] carried out an experiment to measure the viscosity of silver-deionized water nanofluid. They showed that the viscosity of nanofluid enhances with increases the temperature. Sitprasert et al. [18] proposed a nanofluid thermal conductivity model considering the temperature-dependent interfacial layer. They mentioned that this model makes an acceptable prediction for thermal conductivity of nanofluids for flowing and nonflowing fluids. Beck et al. [19] investigated the thermal conductivity of alumina nanoparticles dispersed in ethylene glycol and water. They used a simple model and predicted the effects of the particle size, temperature, and volume fraction of base fluid. Khliyeva et al. [20] proposed a new approach which mixes a limited set of the experimental data (LSED) with correlations of the IBC's versus pressure and heat flux. They examined the pool boiling process for the refrigerant $\mathrm{R} 141 \mathrm{~b}$ and $\mathrm{TiO}_{2}$ nanoparticles. Moreover, an innovative optimization method was proposed to solve convective heat transfer problems [21]. Mosavati et al. $[22,23]$ proposed a new method using the Monte Carlo method to enhance the heat transfer in a step-like cavity.

Improved thermophysical properties of nanofluids as compared with conventional fluid result in an improved heat transfer performance of devices. Generally, the performance of nanofluids is measured in terms of heat transfer coefficient, Nusselt number, pressure drop, and friction factor. Utilization of nanofluids results in higher heat transfer coefficient and Nusselt number due to the increased thermal conductivity. But the use of nanofluids also causes an increase in pressure loss due to the increased viscosity as compared with conventional fluids. Hence, viscosity can be said to act as a limiting factor in performance of nanofluids. Many studies have been conducted in the past to understand the performance of nanofluids. Safaei et al. [24] observed in their study of the flow of nano- and microsized particles through a $90^{\circ}$ pipe bend that maximum pressure is directly proportional to volume concentration and velocity but is inversely proportional to the particle diameter. Chandrasekar et al. [25] developed convective heat transfer through the heated horizontal tube. The Nusselt number enhanced by $12.24 \%$ at $\operatorname{Re}=2275$ tube with nanofluid as compared with distilled water. This enhancement was found to increase further upon the use of wire coil inserts made of stainless steel due to the effects of dispersion or backmixing which flattens the temperature distribution and makes the temperature gradient between the wall and fluid steeper. Jalali et al. [26] reported that high velocity jet injection inside a rectangular microchannel results in a higher Nusselt number due to its higher fluid momentum. Mintsa et al. [27] reported effective thermal conductivity measurements of some nanofluids such as copper oxide/water and alumina/water. They studied the effects of the particle size and various particle volume fractions. Arani et al. [28] studied the characterization of convective heat transfer in turbulent flow of $\mathrm{TiO}_{2}$-water nanofluid. They reported the effect of the mean diameter of nanoparticles on the pressure drop and convective heat transfer. In the numerical investigation of square duct, Heris et al. [29] reported a $68 \%$ enhancement in $\mathrm{CuO} /$ water nanofluids and $60 \%$ enhancement in 


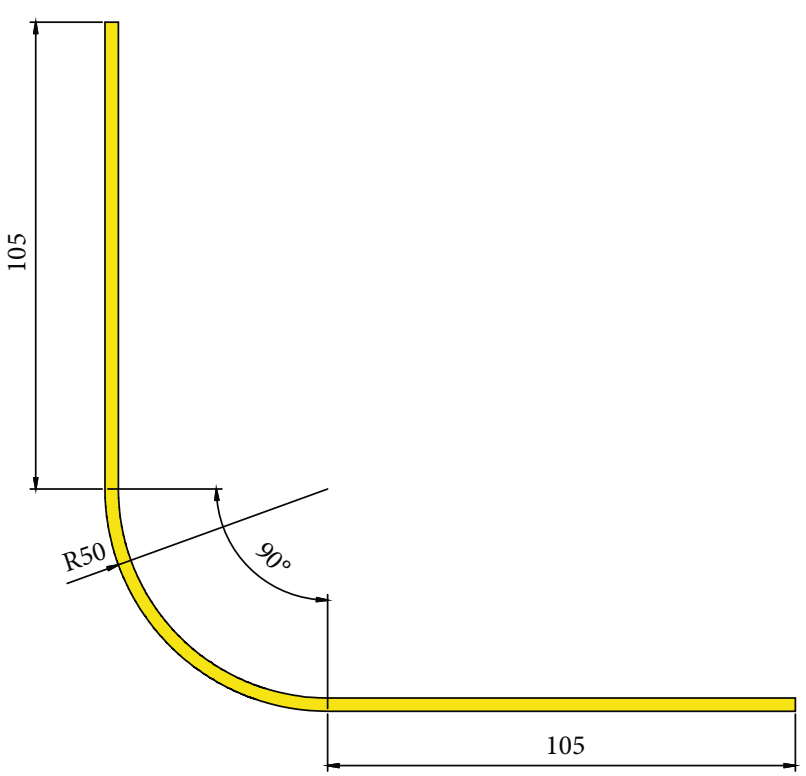

(a) Front view

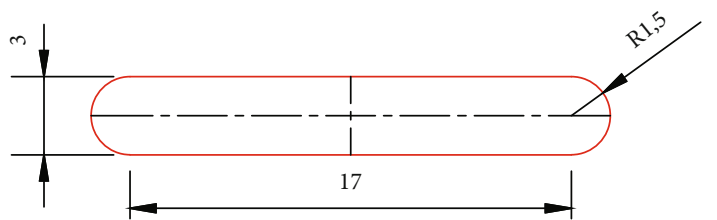

(b) Side view

Figure 1: Schematic of the flat tube.

TABLE 1: Selected parameter for the study.

\begin{tabular}{lc}
\hline Parameter & Range \\
\hline Nanoparticles & $\begin{array}{c}\text { Alumina }\left(\mathrm{Al}_{2} \mathrm{O}_{3}\right), \mathrm{CuO} \text {, and } \\
\text { multiwalled carbon nanotubes }\end{array}$ \\
Conventional base fluid & Water $\left(\mathrm{H}_{2} \mathrm{O}\right)$ \\
Nanoparticle concentration & $0.1-0.5 \% \mathrm{v} / \mathrm{v}$ \\
Inlet fluid temperature & $35-50^{\circ} \mathrm{C}$ \\
Reynolds number & $5000-11000$ \\
\hline
\end{tabular}

alumina/water nanofluid at $4 \%$ volume concentration. Gherasim et al. [30] observed that heat transfer enhancement upon the addition of aluminum oxide nanoparticles into water increases with an increase in the concentration and Reynolds number. Kolsi et al. [31] conducted a study on the effect of double-rotating cylinders on the performance of hybrid nanofluids. It was observed in this study that nanoparticles used in the base fluid enhance the heat transfer rate for the vertical wall by $35.75 \%$. Malvandi et al. [32] conducted a study on $\mathrm{Al}_{2} \mathrm{O}_{3}$-filled vertical annulus and concluded that in the presence of a magnetic field, the advantage of using nanofluid for heat transfer enhancement is reduced. Giwa et al. [33] studied the effects of hybrid nanofluids on natural convection enhancement. The addition of hybrid nanofluids to base fluid was noticed to enhance the thermal as well as flow properties. The results of this study show that the highest value for hav, Nuav, and Qav can be obtained in hybrid nanofluid with 60:40\% weight of $\mathrm{Al}_{2} \mathrm{O}_{3}$ : MWCNT nanoparticles flowing through square cavity. Maximum enhancement of $20.5 \%, 16.2 \%$, and $19.4 \%$ was achieved for $\mathrm{h}, \mathrm{Nu}$, and $\mathrm{Q}$ at $50^{\circ} \mathrm{C}$ as compared with the base fluid. Giwa et al. [34] also investigated the effects of aqueous hybrid ferrofluid (AHF) on the heat transfer through rectangular cavity under magnetic induction. They reported the thermal conductivity of aqueous hybrid ferrofluid for different volume concentrations. The use of hybrid nanofluid was revealed to have a better heat transfer performance than those of monoparticle nanofluids and was also found to depend on the volume concentration, temperature difference, magnetic induction, strength, and direction. Madhesh et al. [35] reported a 48\% enhancement in the heat transfer coefficient upon the addition of hybrid nanofluid to base fluid during the flow through a tubular heat exchanger.

The automobile industry has very high requirement for cooling devices due to the increasing power requirement and need for reducing the size of the cooling device. Radiators are considered as common devices being used in vehicles for cooling various system components and to deliver heat to the atmosphere with the help of air flowing over the radiator tubes [36]. Some studies on different nanofluids like copper oxide, aluminum oxide, copper, and aluminum show that the use of nanofluid instead of conventional base fluid enhances the thermal performance of the radiator $[37,38]$. Furthermore, Elsebay et al. [39] observed that the use of nanofluid instead of conventional base fluid has great impact on the resizing of the radiator flat tube. For a long time, a large amount of research has been carried out on various configurations such as circular cross-sectioned tubes, oval cross-sectioned tubes, flat tubes, and different parameters of radiators [40-43]. Most automotive radiators consist of the flat tubes due to their high-surface-to cross-sectionalarea ratio as compared with circular cross-sectioned tubes which results in a compact heat exchanger with an enhanced thermal performance [44, 45]. Sun et al. [46] developed a model for an elliptical finned-tube heat exchanger and predicted the heat transfer on both the water side and air- side of the elliptical flat tube heat exchanger. Gherasim et al. [47] 


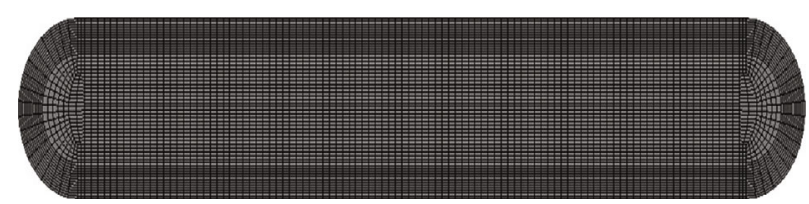

(a) Visualized mesh throughout the flat tube domain

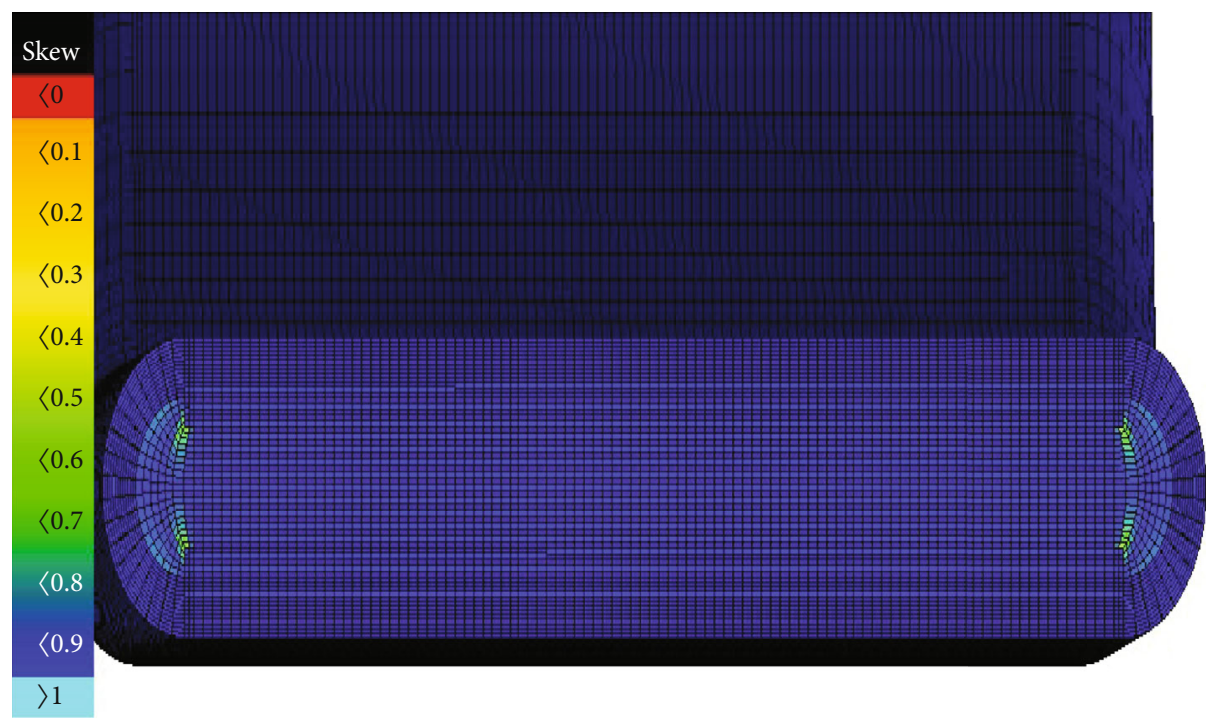

(b) Skewness detailed in mesh generated throughout the flat tube

FIGURE 2: Meshed model of fluid domain.

observed that heat transfer enhancement upon the addition of aluminum oxide nanoparticles into water increases with an increase in concentration and Reynolds number. Akbari et al. [48] observed in their investigation of a ribbed rectangular microchannel that internal ribs can significantly enhance the convective heat transfer within a microchannel; on the other hand, higher ribs can cause a higher friction factor, i.e., performance loss of a microchannel. He et al. [49] reported that heat transfer increases with the volume concentration during the laminar flow as well as turbulent flow but the effect of the particle concentration seems more dominant in the turbulent flow (higher Reynolds number) compared with the laminar flow. Hence, it is observed from previous studies that turbulence in the flow has a significant impact on the thermal performance of the flat tube; a higher turbulent flow provides a better heat transfer performance than laminar. Therefore, the presence of the curvature or bend in the flat tube could be used to produce the turbulence during the flow, which should enhance the thermal performance of the flat tube. Kahani et al. [50] reported in their study that the curvature of the coil and a decrease in pitch coils in the laminar flow through helical coil tube result in the enhancement of the heat transfer rate along with pressure drop. The effect of the curvature was found to be more dominant than the pitch effect in this study.

In a study, Kumar et al. [51] carried out a numerical analysis for the tube bend with $\mathrm{CuO}$ nanofluids at low Reynolds number while this study has been proceeded with three different nanofluids and at high Reynolds number at which most of flat tube applications are used. The nanofluids selected for this study are alumina, $\mathrm{CuO}$, and carbon nanotubes. These nano- fluids are selected due to their capability of producing high heat transfer performance through flat tubes [52, 53]. The study conducted by Selimefendigil et al. [54] also concludes that inclusion of CNT nanoparticles in the base fluid resulted in the performance coefficient enhancement of 52\% at the highest solid volume fraction. The main objective of this study is to carry out a numerical investigation on the performance of the flat tube with a bend of $90^{\circ}$ under the flow of nanofluids at different inlet fluid temperatures and Reynolds numbers.

\section{General Formulations Used}

Thermal conductivity is calculated using a model proposed by Hamilton and Crosser [55] expressed as follows:

$$
\frac{K_{\mathrm{nf}}}{K_{\mathrm{bf}}}=\frac{K_{p}+(n-1) K_{\mathrm{bf}}-\phi(n-1)\left(K_{\mathrm{bf}}-K_{p}\right)}{K_{p}+(n-1) K_{\mathrm{bf}}-\phi\left(K_{\mathrm{bf}}-K_{p}\right)} .
$$

Pak and Choi [56] provided a correlation for determining nanofluid density as follows

$$
\rho_{\mathrm{nf}}=(1-\varphi) \rho_{\mathrm{bf}}+\varphi \rho_{\mathrm{np}}
$$

Brinkman [57] proposed a model for the determination of the effective viscosity as follows

$$
\mu_{\mathrm{nf}}=\frac{1}{(1-\phi)^{2.5}} \mu_{\mathrm{bf}} .
$$


The effective specific heat of the nanofluid is determined using a correlation given by Xuan and Roetzel [58] as follows

$$
\left(C_{p} \rho\right)_{\mathrm{nf}}=\phi\left(\rho C_{p}\right)_{\mathrm{np}}+(1-\phi)\left(\rho C_{p}\right)_{\mathrm{bf}}
$$

The correlation used for the Reynolds number is provided as follows

$$
\operatorname{Re}=\frac{\rho_{\mathrm{nf}} \times v \times D_{h}}{\mu_{\mathrm{nf}}}
$$

The average heat-transfer coefficient is determined as follows

$$
h_{\mathrm{avg}}=\frac{m_{\mathrm{nf}}\left(c_{p}\right)_{\mathrm{nf}}\left(T_{\mathrm{in}}-T_{\mathrm{out}}\right)}{A_{s}\left(T_{B}-T_{w}\right)} .
$$

Here, $T_{B}$ is the bulk-mean temperature which is calculated as follows

$$
T_{B}=\frac{T_{\text {in }}+T_{\text {out }}}{2} .
$$

The general correlation used for determining the Nusselt number is given as follows

$$
N u=\frac{h \times D_{h}}{k} .
$$

\section{Problem Description and Modeling}

The geometry of the flat tube used in this study is clearly presented in Figure 1. In this analysis, it has been assumed that the flat tube with dimensions of $0.310 \mathrm{~m} \times 0.02 \mathrm{~m} \times$ $0.003 \mathrm{~m}$ is bent by $90^{\circ}$ at the center of the tube. The radius of the curvature is shown in Figure 1(a). The tube is curved along both edges of the tube by a radius of $0.0015 \mathrm{~m}$ as shown in Figure 1(b). The bending section is assumed to have a uniform thickness and width throughout the tube, neglecting any distortion or change in width or thickness. The hydraulic diameter is considered an important factor in determining the thermal performance, which represents the effect of the geometry of the tube on the fluid flowing through the tube. The hydraulic diameter is only dependent on the surface area and wetted perimeter. The calculated hydraulic diameter is found to be $0.00535 \mathrm{~m}$ for the given geometry.

In this study, fluid is assumed to be of homogeneous nature with very small particle sizes and volume concentrations. The fluid flowing through the tube is assumed to be incompressible and Newtonian in nature. The velocity and ambient temperature of the air passing through the outer surface of the tube are considered to be constant. The fluid flowing through the tube is considered to be completely turbulent between Reynolds numbers of 5000 to 11000 . This analysis is carried out with the help of the Fluent program available in ANSYS 14.5 which uses the finite volume approach to simulate and to analyze data. The finite volume
TABLE 2: Results obtained during the mesh independency test.

\begin{tabular}{lccc}
\hline Grid & $\begin{array}{c}\text { Grid elements } \\
(1 \times b \times h)\end{array}$ & $\begin{array}{c}\text { Maximum } \\
\text { velocity }\end{array}$ & $\begin{array}{c}\text { Maximum } \\
\text { temperature }\end{array}$ \\
\hline 1 & $200 \times 150 \times 100$ & 0.74315 & 312.5612 \\
2 & $175 \times 130 \times 80$ & 0.74308 & 312.5584 \\
3 & $150 \times 110 \times 70$ & 0.74130 & 312.5561 \\
4 & $150 \times 100 \times 60$ & 0.74025 & 312.5516 \\
5 & $125 \times 90 \times 55$ & 0.73571 & 312.4987 \\
\hline
\end{tabular}

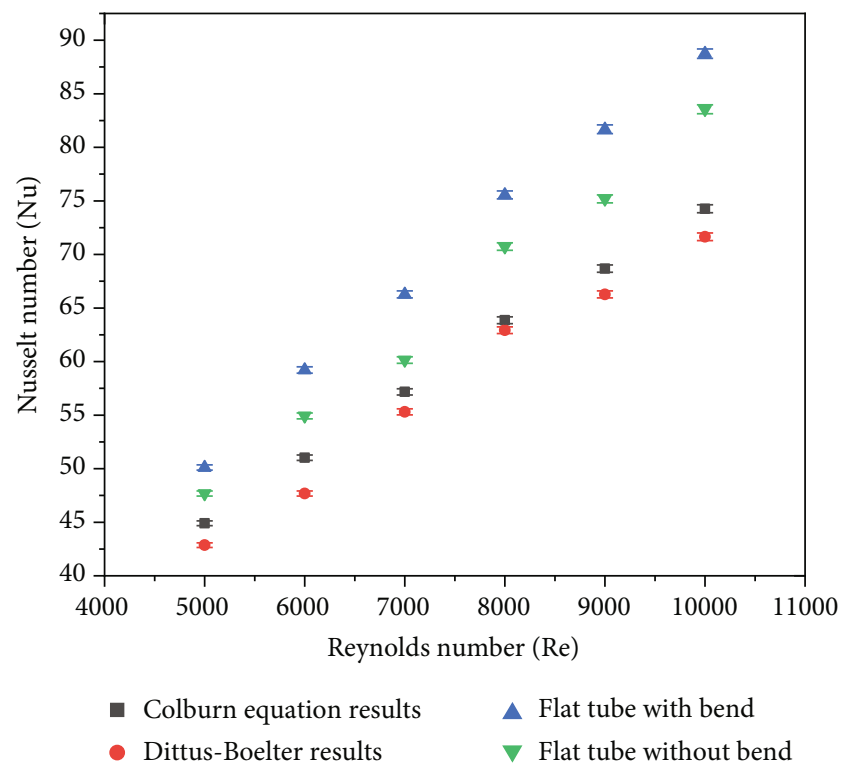

FIGURE 3: Validation of the results of the study with the help of different equations.

approach involves the discretization of the domain into various small segments known as finite volumes or grid cells and then performs operations on these grid cells based on user-defined boundary conditions and input data (materials and type of flow). The finite volume approach utilizes a divergence theorem to convert volume integral in partial differential equations with divergence terms. These terms are calculated at every finite volume in terms of fluxes because flux leaving the finite control volume is the same as flux entering the finite control volume. Integral conservation laws are used in the finite volume approach rather than differential conservation laws. For investigating the performance of fluid flowing through the tube with high turbulence, the $\mathrm{k}-\varepsilon$ model was used. The second-order upwind method solver is chosen for conducting numerical analysis. The second-order upwind method solver was chosen due to higher accuracy as compared with the firstorder upwind solver due to the consideration of three data points instead of two in spatial discretization. The SIMPLEC algorithm for pressure velocity coupling in Ansys fluent is used for this analysis. The solution was converged when the residuals for all the equations dropped below $10^{-6}$. 


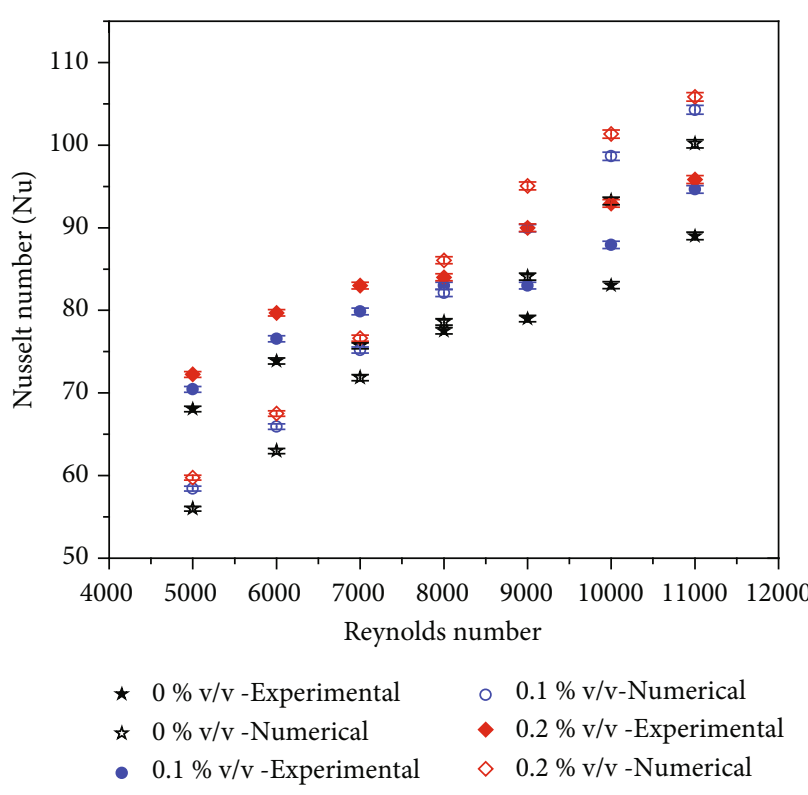

(a)
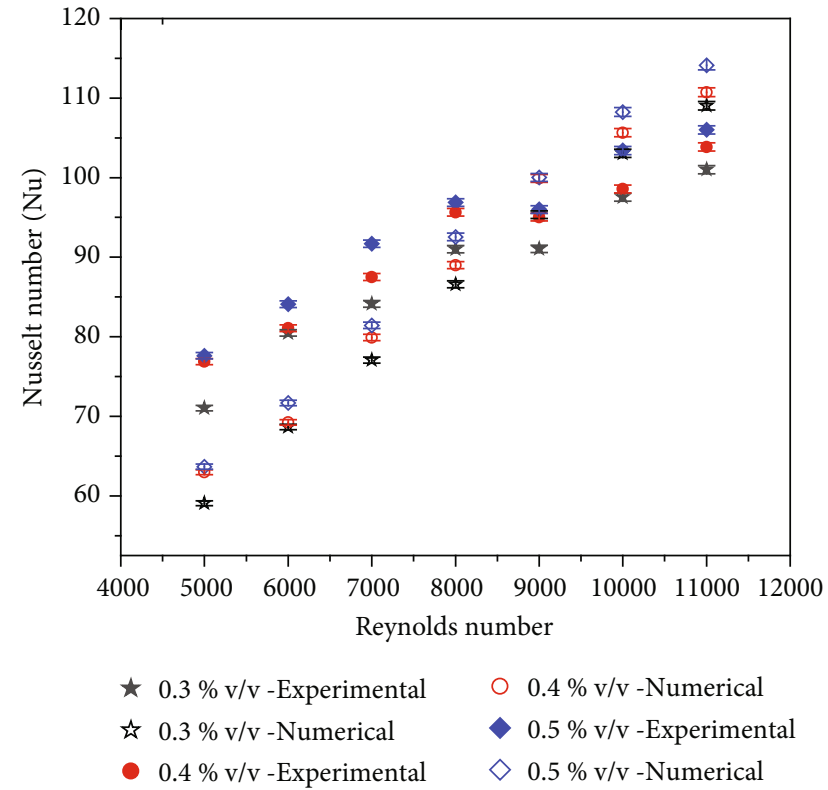

(b)

FiguRE 4: Validation of numerical results at volume concentrations of (a) $0-0.2 \% v / v$ and (b) $0.3 \% v / v-0.5 \% v / v$.

\section{Boundary Condition}

The boundary conditions employed in the present numerical analysis are provided in this section. The ensuing assumptions are made in the present numerical simulations.

(i) The boundary condition at the inlet section of the domain is considered as velocity inlet as inlet velocities of fluid flowing through the flat tube are known

(ii) The turbulence intensity of fluid is kept at $10 \%$

(iii) The constant heat transfer convection coefficient of $150 \mathrm{~W} / \mathrm{m}^{2} \cdot \mathrm{K}$ is assumed throughout tube walls

(iv) The free air stream temperature is kept at $30^{\circ} \mathrm{C}$ (303 K)

(v) The boundary condition at the outlet section of the tube is considered as pressure inlet

The continuity equation, momentum equation, and energy equations for the current problems are as follows:

The continuity equation is

$$
\frac{\partial \rho}{\partial t}+\nabla_{0}(\rho \vec{v})=s_{m}
$$

The momentum equation is

$$
\rho_{\mathrm{nf}}(\nabla . V) V=-\nabla P+\left(\mu_{\mathrm{nf}}+\mu^{t}\right) \nabla^{2} V
$$

The energy equation is

$$
\rho_{n f} C_{p \mathrm{nf}}(\nabla . V) T=k_{\mathrm{nf}} \nabla^{2} T V
$$

The various input parameters selected for this study are provided in Table 1.

\section{Discretization and Mesh Independency Test}

5.1. Discretization. The division of the fluid domain into various grid cells or finite volumes is known as discretization or meshing. A domain can be meshed into various types of elements, i.e., triangular prism, pyramid, hexahedron, and tetrahedron. Structured hexahedron mesh elements are used in our study due to their ability to provide better convergence, less computational time, less computational memory, and high degree of control. The ICEM-CFD program is used for the discretization of the fluid domain. In order to increase the accuracy and precision of results, the density of mesh elements is kept higher at edges as well as the bending section due to the complexity of both the regions and having interaction with outside conditions. The density and type of meshing in the fluid domain can be clearly seen in Figure 2(a). The quality of the generated mesh is analyzed in terms of skewness and orthogonal quality. The skewness and orthogonal quality always lie between 0 (worst element) and 1 (ideal element). In the final meshed model, the skewness and orthogonal quality of meshed elements lie between 0.6 and 1 and 0.65 and 1 , respectively. The skewness quality parameter is clearly shown in Figure 2(b).

5.2. Mesh Independency Test. The mesh independency test was performed to evaluate the exact density of the meshing elements required by maintaining the accuracy of the results at a minimum number of possible elements. The working fluid used for the mesh independency test was water. The inlet temperature and Reynolds number were considered to be $40^{\circ} \mathrm{C}$ and 5000 , respectively, with a free air stream temperature at $30^{\circ} \mathrm{C}$. The initial mesh size, as shown in grid 1 , 


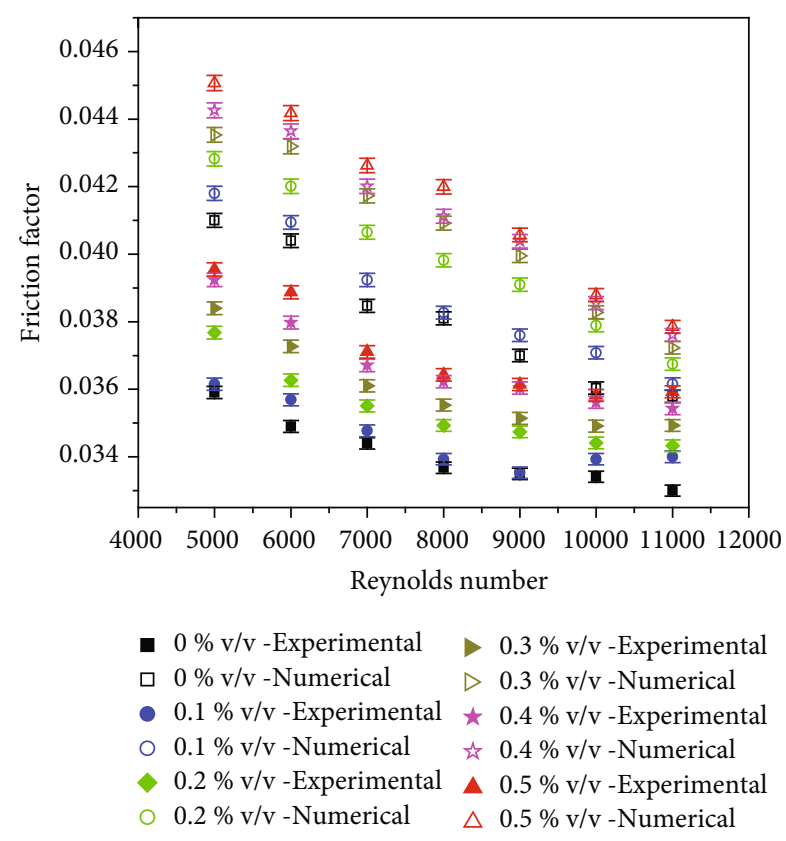

FIgURE 5: Validation of fluid flow parameters.

was kept very fine in order to ensure higher accuracy in results. From various tests conducted with different mesh elements, grids $1,2,3$, and 4 were found to have very insignificant difference between temperature and velocity. The number of iterations and computational time was found to be the lowest for grid 4 as compared with grids 1, 2, and 3 . So, based on the results presented in Table 2, grid 4 was found to be convenient for further study.

5.3. Validation of the Numerical Procedure. In order to validate the accuracy of the current numerical model, our numerical results were compared with the results obtained from Colburn and Dittus-Boelter equations as presented in Figure 3. The average percentage differences obtained after comparing results of this study with Colburn equation and Boelter equation are $16.3 \%$ and $20.1 \%$, respectively. Figure 3 also illustrates the results obtained for the flow through a straight flat tube without a bend which has average percentage differences of $8.04 \%$ and $12.13 \%$ from Colburn and Dittus-Boelter equation results. The results of the flat tube without a bend were compared with results of the flat tube with a bend in order to know the difference between performances of both tubes. The Nusselt number for the flow through the bent tube was found to be $8 \%$ higher than the straight tube. This enhancement in the heat transfer is seen to increase with the increase in the Reynolds number, i.e., a higher Reynolds number will have a more dominant effect of turbulence due to the bend. This supports the decision of selecting the flat tube with a bend for this study.

\section{Results and Discussion}

6.1. Validation of Computed Results. Heat transfer and flow parameters calculated during the study were validated with the help of experimental and numerical results as shown in

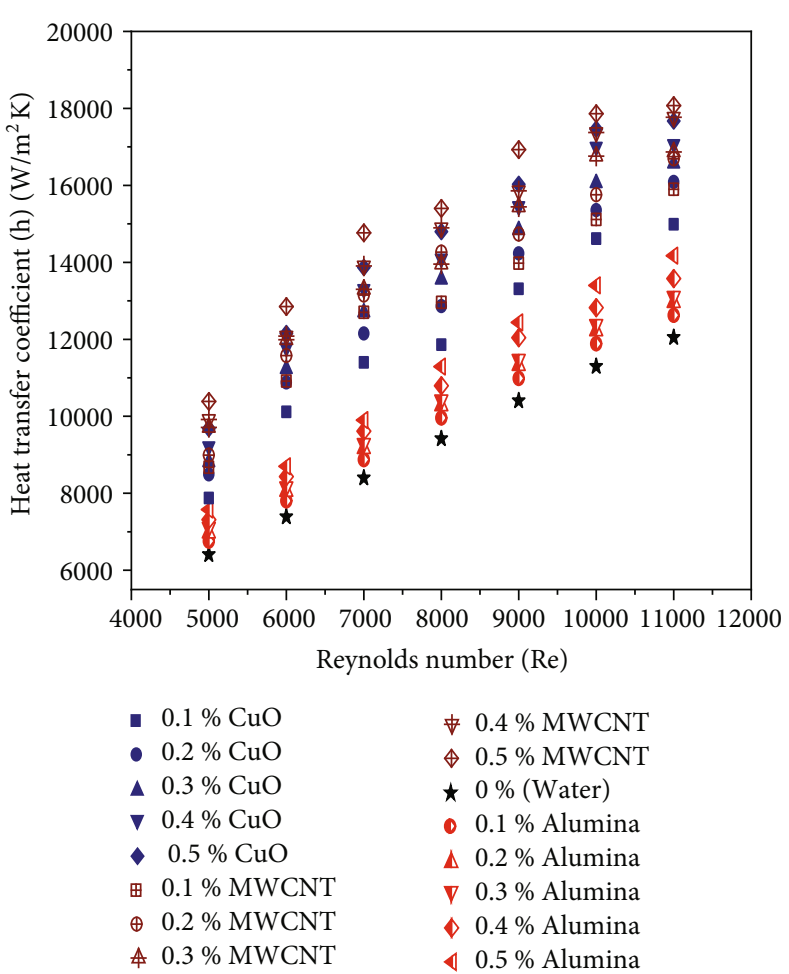

Figure 6: Variations in heat transfer coefficient at $35^{\circ} \mathrm{C}$.

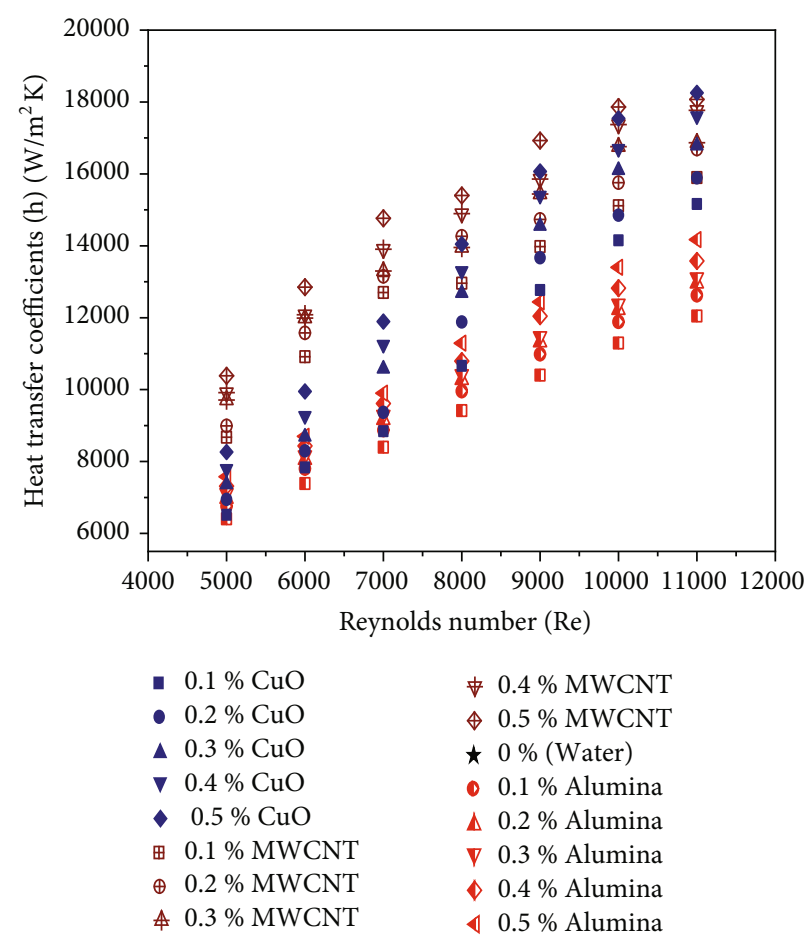

FIGURE 7: Variations in heat transfer coefficient at $40^{\circ} \mathrm{C}$.

Figure 4. Some experiments were performed on the available test rig [59] to validate the results of numerical analysis. The overall average deviation obtained between numerical results and experimental results was found to be around $10 \%$. The 

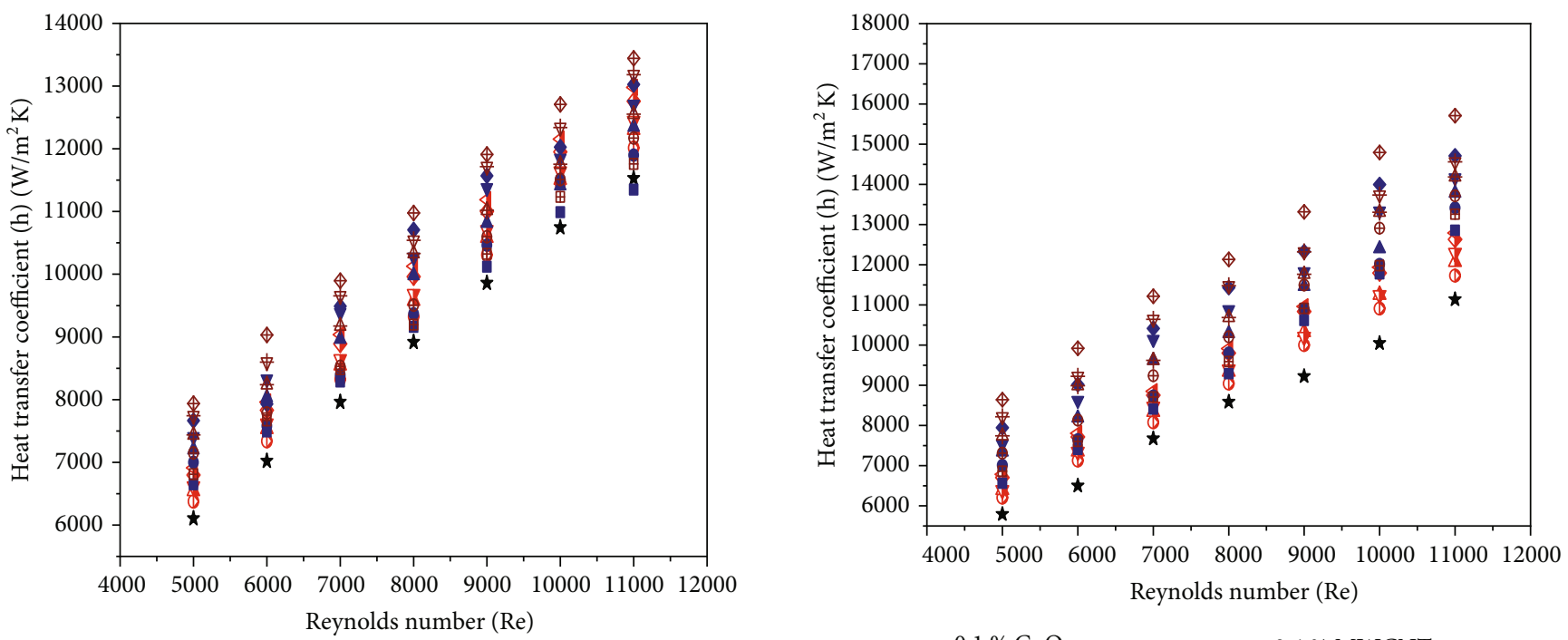

\begin{tabular}{|c|c|c|c|}
\hline & $0.1 \% \mathrm{v} / \mathrm{v} \mathrm{CuO}$ & 中 & $0.4 \% \mathrm{v} / \mathrm{v}$ MWCNT \\
\hline - & $0.2 \% \mathrm{v} / \mathrm{v} \mathrm{CuO}$ & $\oplus$ & $0.5 \% \mathrm{v} / \mathrm{v}$ MWCNT \\
\hline $\boldsymbol{\Delta}$ & $0.3 \% \mathrm{v} / \mathrm{vCuO}$ & $\star$ & $0 \%$ (Water) \\
\hline $\boldsymbol{\nabla}$ & $0.4 \% \mathrm{v} / \mathrm{v} \mathrm{CuO}$ & 0 & $0.1 \%$ Alumina \\
\hline$\diamond$ & $0.5 \% \mathrm{v} / \mathrm{v} \mathrm{CuO}$ & $\Delta$ & $0.2 \%$ Alumina \\
\hline 田 & $0.1 \% \mathrm{v} / \mathrm{v}$ MWCNT & $\nabla$ & $0.3 \%$ Alumina \\
\hline$\theta$ & $0.2 \% \mathrm{v} / \mathrm{vMWCNT}$ & $\diamond$ & $0.4 \%$ Alumina \\
\hline 4 & $0.3 \% \mathrm{v} / \mathrm{v}$ MWCNT & 4 & $0.5 \%$ Alumina \\
\hline
\end{tabular}

Figure 8: Variations in heat transfer coefficient at $45^{\circ} \mathrm{C}$.

deviation was found to be more at lower Reynolds as compared with higher Reynolds numbers. The maximum deviation of $17 \%$ was obtained at a Reynolds number of 5000, and a minimum deviation of $5 \%$ is obtained at a Reynolds number of 8000. It is also observed that at a lower Reynolds number, the experimental heat transfer performance of nanofluid shows higher values than the predicted numerical results, while at a higher Reynolds number, it is lower compared with the numerical results. Fluid flow parameters were validated by comparing the numerical friction factor with the experimental friction factor as shown in Figure 5. The average deviation of $12 \%$ was calculated between the experimental data and numerical data for the friction factor. Maximum deviation lies between 12 and 15\% at a Reynolds number of 5000 at different volume concentrations. Deviation percentage is reduced by increasing the Reynolds number. At a Reynolds number of 11000 minimum, the deviation of $6-9 \%$ is observed at different volume concentrations.

6.2. Heat Transfer Coefficient. The study of variation in the heat transfer coefficient shows that the heat transfer coefficient increases with alumina, $\mathrm{CuO}$, and multiwalled carbon nanotube volume concentrations as well as a Reynolds number. The variation in the heat transfer coefficient at $35^{\circ} \mathrm{C}$ is presented in Figure 6. At a Reynolds number of 5000, the heat transfer coefficient is reported to increase from $6400 \mathrm{~W} / \mathrm{m}^{2} \cdot \mathrm{K}$ to $7575 \mathrm{~W} / \mathrm{m}^{2} \cdot \mathrm{K}$ when the volume concentration is increased from $0 \%$ to $0.5 \%$. At a Reynolds number of 8000 , the heat transfer coefficient is increased from 5 to $19 \%$ with an increase in the alumina nanoparticle concentration
- $0.1 \% \mathrm{CuO}$
- $0.2 \% \mathrm{CuO}$
$\forall 0.4 \%$ MWCNT
v $0.4 \% \mathrm{CuO}$
- $0.5 \% \mathrm{CuO}$
田 $0.1 \%$ MWCNT
$\oplus 0.2 \%$ MWCNT
$\star 0.5 \%$ MWCNT
$\star 0 \%$ (Water)
- $0.1 \%$ Alumina
$\triangle 0.2 \%$ Alumina
จ $0.3 \%$ Alumina
$\triangleright 0.4 \%$ Alumina
4 $0.3 \%$ MWCNT $\quad$ \& $0.5 \%$ Alumina

Figure 9: Heat transfer coefficient at $50^{\circ} \mathrm{C}$.

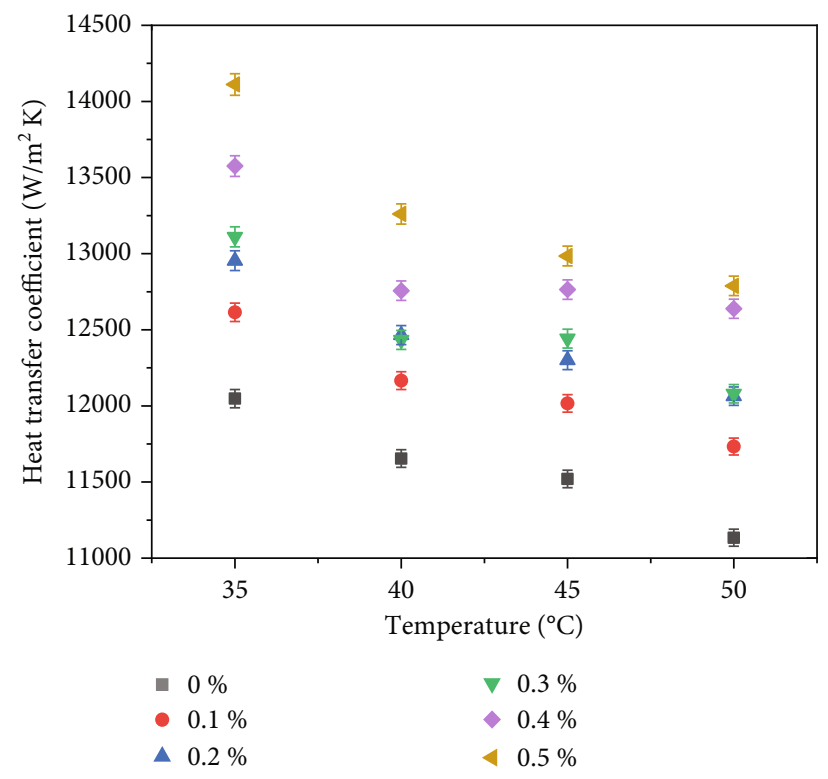

FIgURE 10: Heat transfer coefficient under different temperatures at a Reynolds number of 11000 .

from 0.1 to $0.5 \%$. At a Reynolds number of 11000 , the heat transfer coefficient is increased from $12050 \mathrm{~W} / \mathrm{m}^{2} \cdot \mathrm{K}$ to $14175 \mathrm{~W} / \mathrm{m}^{2} \cdot \mathrm{K}$ by increasing the alumina volume concentration from $0 \%$ to $0.5 \%$. The heat transfer coefficient is enhanced by $16-19 \%$ by increasing the Reynolds number from 5000 to 11000 at a volume concentration of $0.5 \%$. It can be also observed from this study that the use of $\mathrm{CuO}$ 


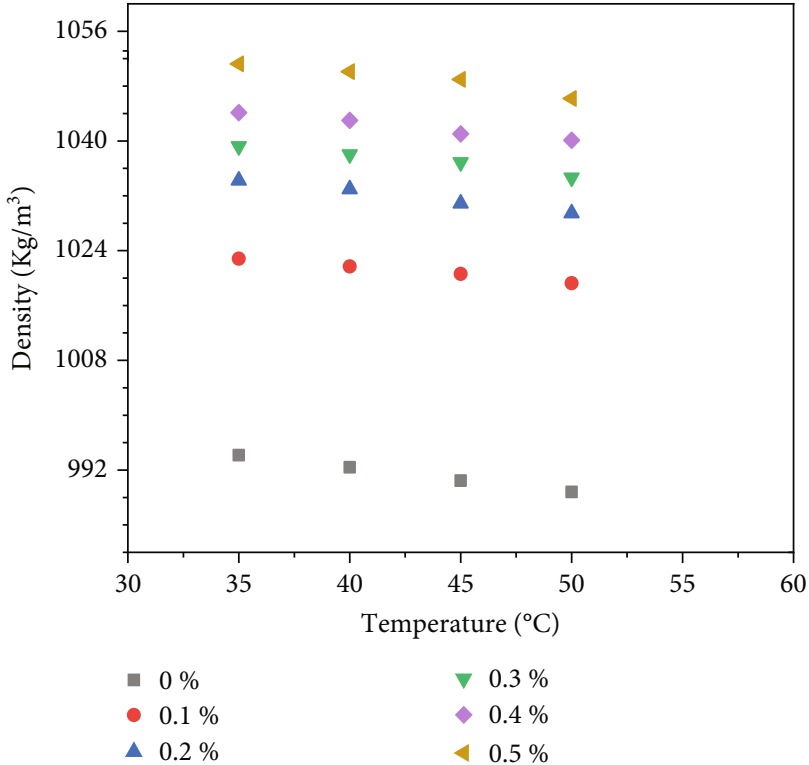

(a) Density

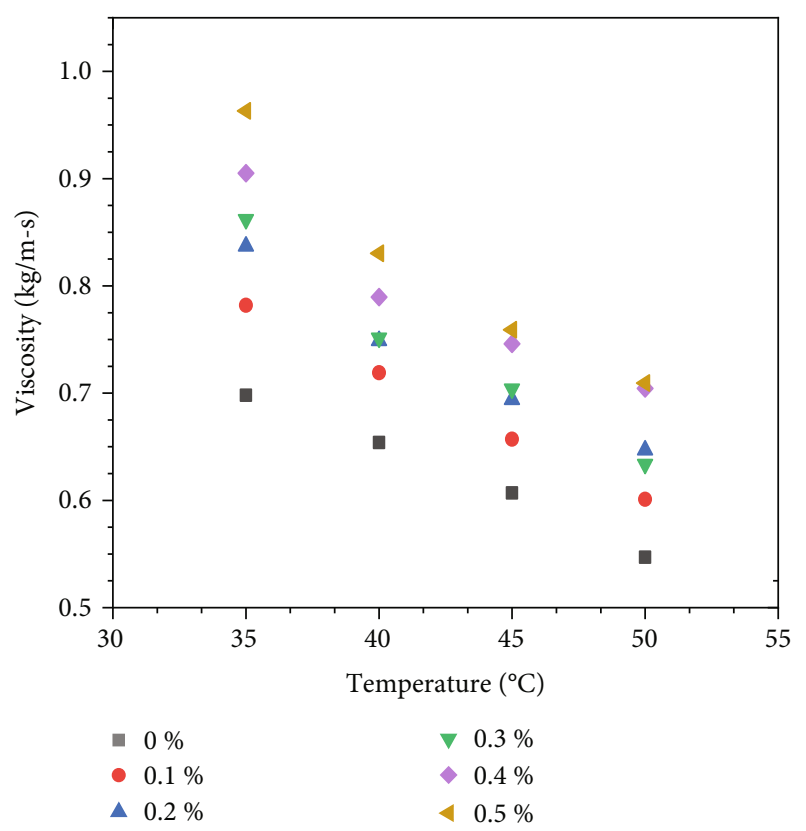

(b) Viscosity

FIGURE 11: Density and viscosity calculated from empirical correlations.

and carbon nanotubes provides higher heat transfer coefficients than alumina nanofluids. When $\mathrm{CuO}$ is used instead of alumina, a nanoparticle minimum enhancement of $26 \%$ is obtained at $0.1 \%$ volume concentration. At $35^{\circ} \mathrm{C}$ and a Reynolds number of 5000, the heat transfer coefficient is reported to increase from $7875 \mathrm{~W} / \mathrm{m}^{2} \cdot \mathrm{K}$ to $9683 \mathrm{~W} / \mathrm{m}^{2} \cdot \mathrm{K}$ when the volume concentration is increased from $0 \%$ to $0.5 \%$. The maximum enhancement of $48 \%$ from base fluid was obtained when the volume concentration is increased to $0.5 \%$ at a Reynolds number of 11000 . At a Reynolds number of 11000 , the heat transfer coefficient is increased to $17670 \mathrm{~W} / \mathrm{m}^{2} \cdot \mathrm{K}$ from $14987 \mathrm{~W} / \mathrm{m}^{2} \cdot \mathrm{K}$ upon increase in the volume concentration from $0.1 \%$ to $0.5 \%$. In the case of carbon nanotubes, the maximum enhancement of 55\% from base fluid was observed at a Reynolds number of 10000 and volume concentration of $0.5 \%$ while the minimum enhancement of $30 \%$ is observed at $0.1 \% v / v$. At $35^{\circ} \mathrm{C}$ and a Reynolds number of 5000, the heat transfer coefficient is reported to increase from $8680 \mathrm{~W} / \mathrm{m}^{2} \cdot \mathrm{K}$ to $10493 \mathrm{~W} / \mathrm{m}^{2} \cdot \mathrm{K}$ when the volume concentration is increased from $0 \%$ to $0.5 \%$.

The variation in the heat transfer coefficient with an increase in the nanoparticle volume concentration and Reynolds number at $40^{\circ} \mathrm{C}$ is provided in Figure 7 . At $40^{\circ} \mathrm{C}$ and a Reynolds number of 5000, the heat transfer coefficient increased from $6250 \mathrm{~W} / \mathrm{m}^{2} \cdot \mathrm{K}$ to $7044 \mathrm{~W} / \mathrm{m}^{2} \cdot \mathrm{K}$ by increasing the alumina nanoparticle volume concentration from $0 \%$ to $0.5 \%$. The heat transfer is increased to $13265 \mathrm{~W} / \mathrm{m}^{2} \cdot \mathrm{K}$ at a Reynolds number of 11000 and the alumina volume concentration of $0.5 \%$. At a Reynolds number of 8000 and temperature of $40^{\circ} \mathrm{C}$, the heat transfer coefficient is increased from $6 \%$ to $14 \%$ with an increase in the volume concentration from $0.1 \%$ to $0.5 \%$. The heat transfer coefficient is enhanced from 14 to $16 \%$ with an increase in the Reynolds number from 5000 to 11000 at volume concentration of $0.5 \%$. When $\mathrm{CuO}$ is used instead of alumina, a nanoparticle minimum enhancement of $23 \%$ from base fluid is obtained at $0.1 \%$ volume concentration at a Reynolds number of 5000 . At $40^{\circ} \mathrm{C}$ and a Reynolds number of 11000 , the heat transfer coefficient increased from $15664 \mathrm{~W} / \mathrm{m}^{2} \cdot \mathrm{K}$ to $18436 \mathrm{~W} / \mathrm{m}^{2} \cdot \mathrm{K}$ by increasing the $\mathrm{CuO}$ nanoparticle volume concentration from $0 \%$ to $0.5 \%$. A maximum enhancement of $54 \%$ from base fluid was obtained when the volume concentration is increased to $0.5 \%$ from $0.1 \%$ at a Reynolds number of 11000. In the case of carbon nanotubes, a maximum enhancement of $52 \%$ from base fluid was observed at a Reynolds number of 11000 and volume concentration of $0.5 \%$ while a minimum enhancement of $27 \%$ is observed at $0.1 \% v / v$. At a Reynolds number of 11000 , the heat transfer coefficient increased from $8675 \mathrm{~W} / \mathrm{m}^{2} \cdot \mathrm{K}$ to $10383 \mathrm{~W} / \mathrm{m}^{2} \cdot \mathrm{K}$ by increasing the nanotube volume concentration from $0.1 \%$ to $0.5 \%$.

The heat transfer coefficient variation at $45^{\circ} \mathrm{C}$ is presented in Figure 8. It can be seen that increasing the Reynolds number from 5000 to 11000 increased the heat transfer coefficient from 6900 to $12975 \mathrm{~W} / \mathrm{m}^{2} \cdot \mathrm{K}$ at the volume concentration of $0.5 \%$. In addition, decreasing the volume concentration to $0.1 \%$ also decreased the heat transfer coefficient to $11500 \mathrm{~W} / \mathrm{m}^{2} \cdot \mathrm{K}$ at a Reynolds number of 12000. At a Reynolds number of 10000 , it can be observed that increasing the alumina volume concentration from 0.1 to $0.5 \%$ increased the heat transfer coefficient up to $13 \%$. The heat transfer coefficient is enhanced from $12 \%$ to $15 \%$ upon increasing the Reynolds number from 5000 to 11000 at a volume concentration of $0.5 \%$. When $\mathrm{CuO}$ is used instead of an alumina nanoparticle, a minimum enhancement of $20 \%$ from base fluid is obtained at $0.1 \%$ volume concentration. A maximum enhancement of $39 \%$ from base 
fluid is obtained when the volume concentration is increased to $0.5 \%$ at a Reynolds number of 11000 . At a Reynolds number of 11000 , the heat transfer coefficient increased from $14103 \mathrm{~W} / \mathrm{m}^{2} \cdot \mathrm{K}$ to $16369 \mathrm{~W} / \mathrm{m}^{2} \cdot \mathrm{K}$ by increasing the $\mathrm{CuO}$ nanoparticle volume concentration from $0 \%$ to $0.5 \%$. In the case of carbon nanotubes, the maximum enhancement of $44 \%$ from base fluid was observed at a Reynolds number of 10000 and volume concentration of $0.5 \%$ while a minimum enhancement of $18 \%$ is observed at $0.1 \% v / v$. At $45^{\circ} \mathrm{C}$ and a Reynolds number of 11000 , the heat transfer coefficient increased from $14703 \mathrm{~W} / \mathrm{m}^{2} \cdot \mathrm{K}$ to $17179 \mathrm{~W} / \mathrm{m}^{2} \cdot \mathrm{K}$ by increasing the volume concentration from $0 \%$ to $0.5 \%$.

The effect of the variation of the Reynolds number and alumina concentration on the heat transfer coefficient at $50^{\circ} \mathrm{C}$ is presented in Figure 9. At $50^{\circ} \mathrm{C}$, it is found that by increasing the alumina volume concentration from 0 to $0.5 \%$ at a Reynolds number of 5000 , the heat transfer coefficient increases from $5800 \mathrm{~W} / \mathrm{m}^{2} \cdot \mathrm{K}$ to $6775 \mathrm{~W} / \mathrm{m}^{2} \cdot \mathrm{K}$ and it is increased to $12790 \mathrm{~W} / \mathrm{m}^{2} \cdot \mathrm{K}$ when a Reynolds number is increased to 11000 . At the Reynolds number of 9000 and $50^{\circ} \mathrm{C}$, heat transfer coefficient is increased from $7 \%$ to $16 \%$ with an increase in the volume concentration from $0.1 \%$ to $0.5 \%$. The heat transfer coefficient is enhanced from $15 \%$ to $17 \%$ with an increase in the Reynolds number from 5000 to 11000 at the volume concentration of $0.5 \%$. When $\mathrm{CuO}$ is used instead of an alumina nanoparticle, a minimum enhancement of $20 \%$ from base fluid is obtained at $0.1 \%$ volume concentration. A maximum enhancement of $39 \%$ from base fluid is obtained when the volume concentration is increased to $0.5 \%$ at a Reynolds number of 11000 . At $50^{\circ} \mathrm{C}$, it is observed that by increasing the $\mathrm{CuO}$ nanoparticle volume concentration from 0 to $0.5 \%$ at a Reynolds number of 11000 , the heat transfer coefficient increases from $12857 \mathrm{~W} / \mathrm{m}^{2} \cdot \mathrm{K}$ to $14711 \mathrm{~W} / \mathrm{m}^{2} \cdot \mathrm{K}$. In the case of carbon nanotubes, the maximum enhancement of $44 \%$ from base fluid was observed at a Reynolds number of 10000 and volume concentration of $0.5 \%$ while the minimum enhancement of $17 \%$ is observed at $0.1 \% v / v$. In the case of nanotubes, upon increasing the volume concentration from 0 to $0.5 \%$ at a Reynolds number of 11000 , the heat transfer coefficient increases from $13264 \mathrm{~W} / \mathrm{m}^{2} \cdot \mathrm{K}$ to $15858 \mathrm{~W} / \mathrm{m}^{2} \cdot \mathrm{K}$.

The increase in the heat transfer with an increase in the volume concentration is due to the suspension of particles with high thermal conductivity. When nanoparticles are added into the base fluid, the thermal conductivity of base fluid increases. Chen et al. [60] and Wen and Ding [61] proposed a similar reason in their studies for increasing the heat transfer performance of nanofluids. The Brownian motion of particles causes a delayed thermal boundary layer at the wall surface of the tube which improves the performance of the tube. A similar observation was also reported by Arani and Amani [28] in their study. The energy interaction between nanoparticles dispersed into the base fluid is also responsible for the enhancement of the heat transfer coefficient.

The heat transfer performance is also observed to be significantly influenced by the inlet temperature. The heat transfer coefficient is observed to decrease with the increase in the fluid inlet temperature. This decrease is due to the rise

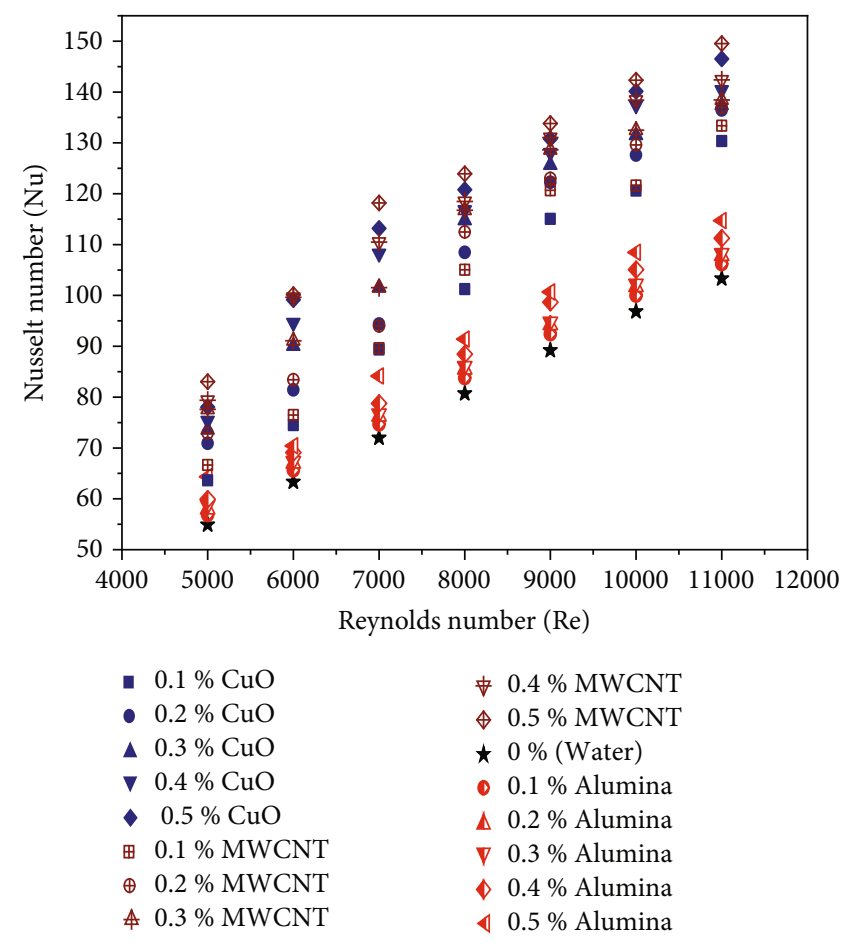

Figure 12: Nusselt number at a temperature of $35^{\circ} \mathrm{C}$.

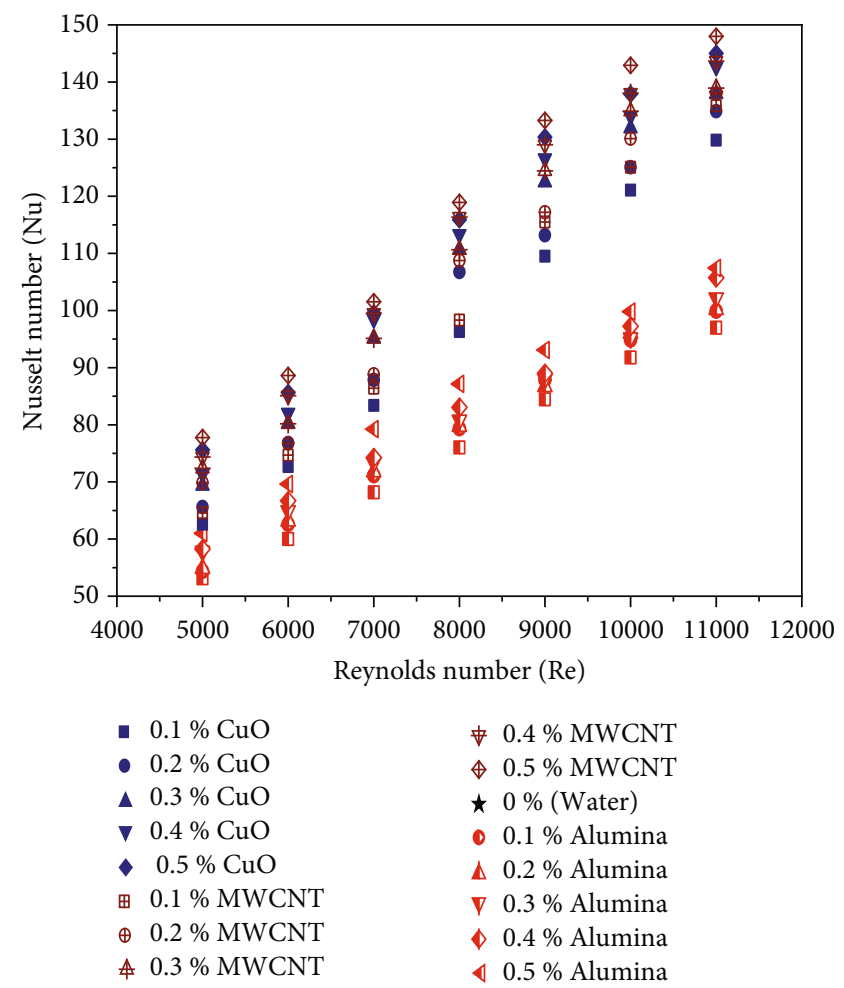

Figure 13: Nusselt number at $40^{\circ} \mathrm{C}$.

in the inlet temperature, which is clearly visible in Figure 10. The heat transfer coefficient is reduced by $8 \%$ when the temperature increased from 35 to $50^{\circ} \mathrm{C}$ at an alumina concentration of $0.1 \%$ and a Reynolds number of 5000 . At 


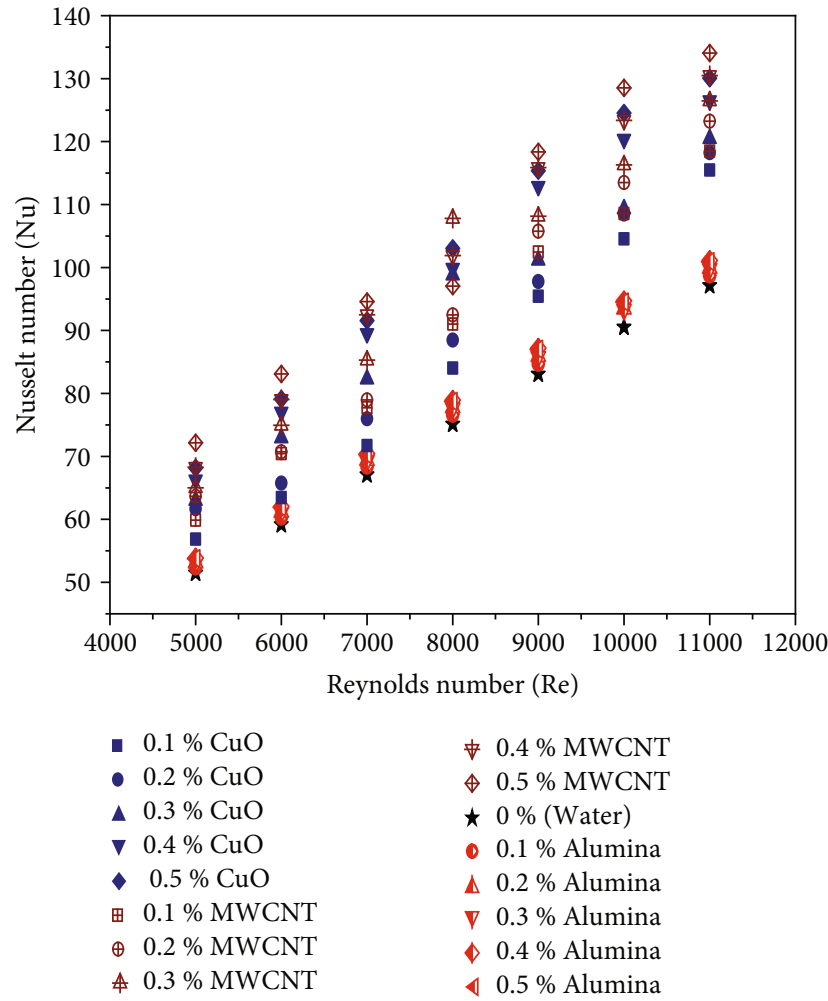

Figure 14: Nusselt number at $45^{\circ} \mathrm{C}$.

a Reynolds number of 11000 and alumina concentration of $0.5 \%$, increasing the fluid temperature brought about a $10 \%$ reduction in the heat transfer coefficient. Similar trends were reported for both carbon nanotubes and $\mathrm{CuO}$ as well. Both $\mathrm{CuO}$ and carbon nanotubes reported reductions of $6 \%$ and $9 \%$, respectively.

The factor responsible for this decrease could be a higher and prominent decrease in viscosity of nanofluid. The variation of viscosity and density in Figures 11(a) and 11(b) clearly shows that the decrease in the density is very low while on the other hand, the decrease in the viscosity is considerable due to the increase in the temperature of nanofluids. Naraki et al. [62] reported a similar trend for a heat transfer performance of $\mathrm{CuO}$ nanoparticles. Apart from this, the validation of thermophysical properties, i.e., viscosity and density, has been measured experimentally. The density and viscosity has been measured experimentally with a specific gravity bottle and viscometer, respectively. The error between the experimental- and numerical-based thermophysical properties was approximately $\pm 5 \%$. So based on the experimental data and numerical data of thermophysical properties have been used in experimental and numerical study, respectively. For the low concentration of nanoparticles, nanofluids showed the Newtonian behavior, while with the increase in particles concentration, the nanofluid behavior changed to non-Newtonian. The increase in viscosity with increasing of the nanoparticle loading also leads to a clustering phenomenon. With increasing of the concentration, the internal stresses become significant, which also contribute to the rise in viscosity of nanofluids as compared with the base fluid.

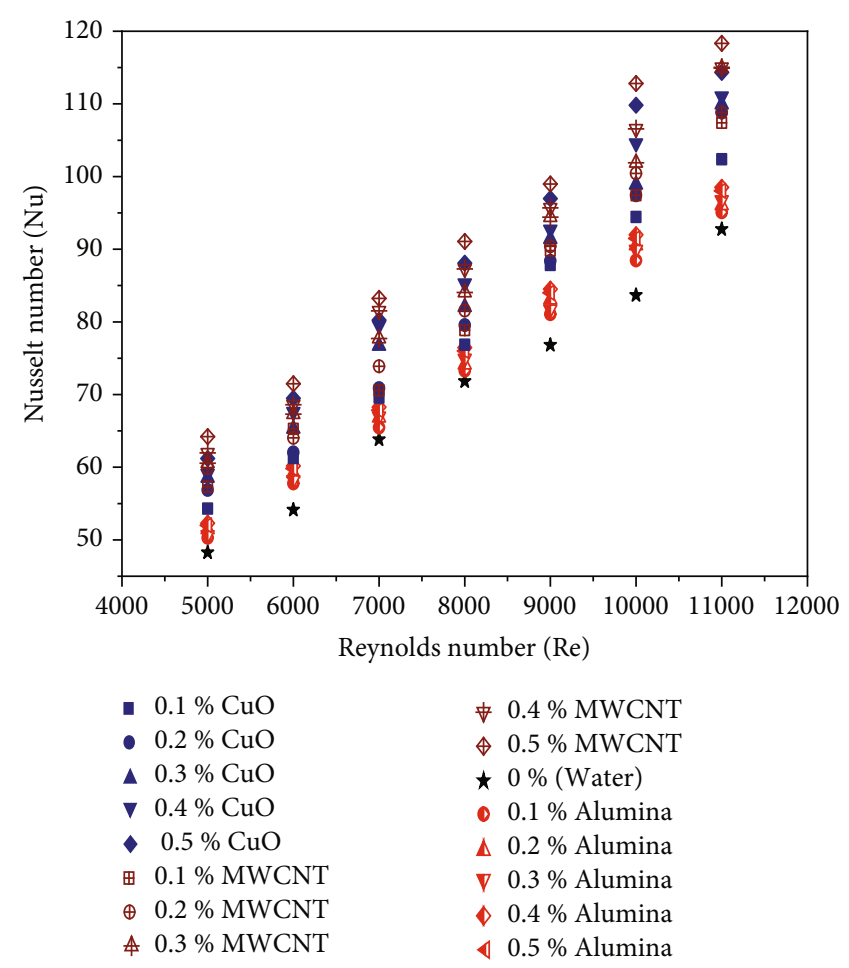

Figure 15: Nusselt number at $50^{\circ} \mathrm{C}$.

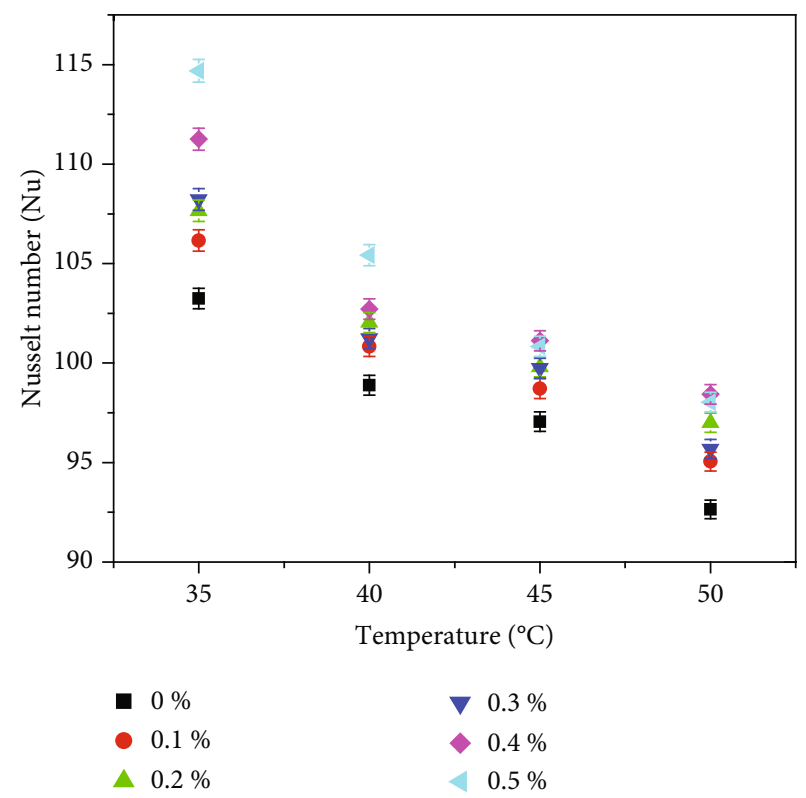

FIgURE 16: Variations in the Nusselt number at various temperatures under a Reynolds number of 11000 .

6.3. Nusselt Number. The Nusselt number provides better understanding of the heat transfer performance due to its dimensionless nature and its dependence upon both the heat transfer coefficient and the thermal conductivity. The behavior of the Nusselt number with an increasing Reynolds number and volume concentrations at temperatures between $35^{\circ} \mathrm{C}$ and $50^{\circ} \mathrm{C}$ is provided in Figures $12-15$. It is found that 


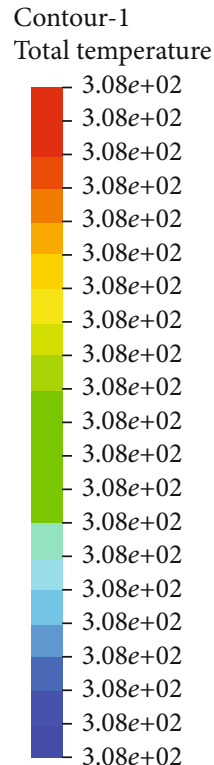

$[\mathrm{k}]$

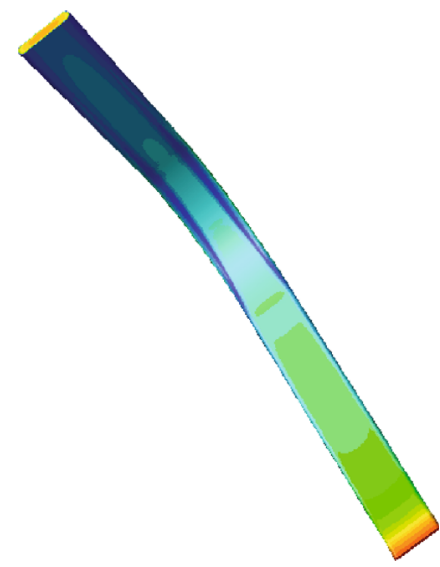

(a)

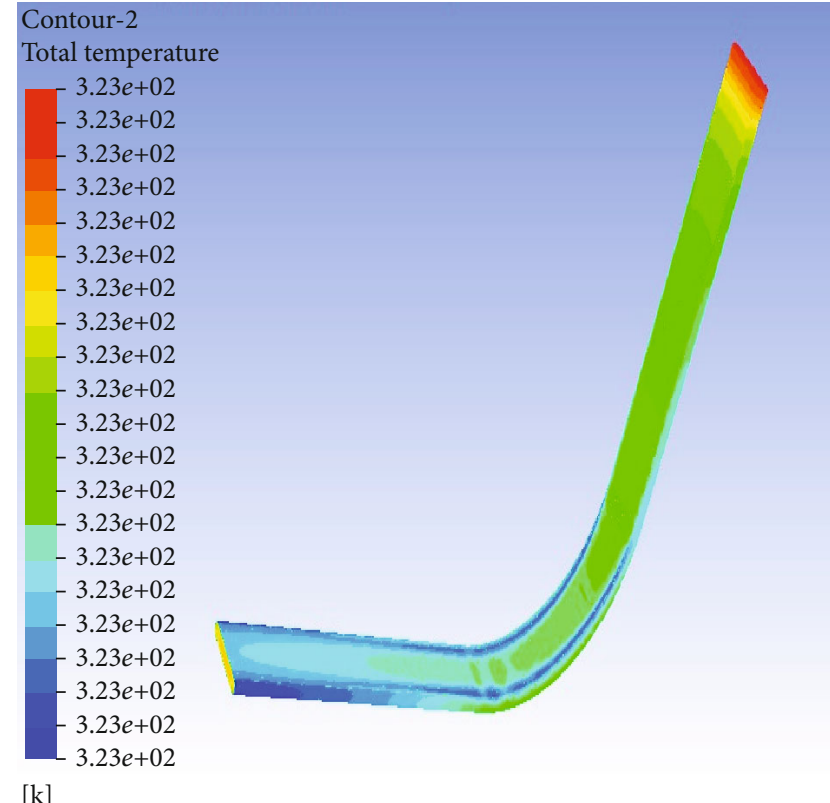

(b)

Figure 17: Temperature contours temperature ( $T$ ) and Reynolds number (Re); (a) $T=35^{\circ} \mathrm{C}$ and $\operatorname{Re}=6000$; (b) $T=50^{\circ} \mathrm{C}$ and $\operatorname{Re}=11000$.

the Nusselt number is proportional to both the volume concentration and the Reynolds number. On the other hand, as shown in Figure 16, the Nusselt number decreases with an increase in the inlet fluid temperature. At $0.1 \%$ alumina nanoparticle concentration and inlet fluid temperature of $35^{\circ} \mathrm{C}$, the Nusselt number is $5 \%$ higher than base fluid under a Reynolds number of 5000 . At $0.5 \%$ alumina nanoparticle concentration and a Reynolds number of 5000, the Nusselt number is enhanced by $12 \%$ compared with the base fluid and this is further increased to $15 \%$ upon increasing the Reynolds number to 11000 . At an inlet fluid temperature of $50^{\circ} \mathrm{C}$ and volume concentration of $0.1 \%$, the Nusselt number is $4 \%$ higher than the base fluid under the Reynolds number of 5000 . When the alumina concentration is increased to $0.5 \%$, the Nusselt number is noted to be $8 \%$ higher than base fluid. At $35^{\circ} \mathrm{C}$, in the case of both $\mathrm{CuO}$ and carbon nanotubes, the Nusselt number is increased by $16 \%$ and $21 \%$, respectively, at a volume concentration of $0.1 \%$ and a Reynolds number of 5000, while the Reynolds number is increased to 11000; the increase in the Nusselt number is around $32 \%$ and $40 \%$. The maximum Nusselt number is obtained at a fluid inlet temperature of $35^{\circ} \mathrm{C}$, and it decreases when it is increased to $50^{\circ} \mathrm{C}$ as shown in Figure 16 . At $50^{\circ} \mathrm{C}$, the increase in the Nusselt number from the base fluid is $12 \%$ and $18 \%$ for $\mathrm{CuO}$ and carbon nanotubes, respectively, at a volume concentration of $0.1 \%$ and a Reynolds number of 5000. The carbon nanotube nanoparticle provides a better heat transfer performance than both $\mathrm{CuO}$ and alumina. Various factors are responsible for the variation in the Nusselt number which has already been discussed in the heat transfer coefficient section. The effect of increasing the inlet fluid temperature on the Nusselt number at a Reynolds number of 11000 is shown in Figure 16. The temperature contours for the flat tube are shown in
Figure 17. It is clearly visible in Figure 17 that the effect of the bend in the flat tube at a Reynolds number of 11000 as shown in Figure 17(b) is more prominent as compared with the Reynolds number of 6000 as shown in Figure 17(a). Hence, the enhancement in the heat transfer performance of the flat tube with the bend as compared with performance of the tube without the bend is higher at a higher Reynolds number. Similar trends for both the heat transfer coefficient and Nusselt number were observed by Sharma et al. [52] in the study of the flow of nanofluid through the flat tube.

6.4. Variations in the Pressure Drop and Friction Factor. The pressure drop is dependent on various properties of the fluid like the Reynolds number, viscosity, and density. The contours of the pressure drop at various temperatures and pressures are shown in Figure 18. Variations in the pressure drop upon changes in the alumina nanoparticle, $\mathrm{CuO}$, Carbon nanotube volume concentration, and Reynolds number at different temperatures of $35^{\circ} \mathrm{C}, 40^{\circ} \mathrm{C}, 45^{\circ} \mathrm{C}$, and $50^{\circ} \mathrm{C}$ have been presented in Figures 19-22, respectively. The effect of increasing the temperature at a Reynolds number of 11000 on the pressure drop is shown in Figure 23. General trends observed in this study show that the pressure drop is increased by increasing the volume concentration and Reynolds number; however, the pressure drop is decreased by increasing the inlet fluid temperatures. At $35^{\circ} \mathrm{C}$ and a volume concentration of $0.1 \%$ alumina, the pressure drop is $20 \%$ higher than base fluid under the constant Reynolds number $(\mathrm{Re}=5000)$. When the alumina volume concentration is increased from $0.1 \%$ to $0.5 \%$, the pressure drop is also increased by $72.3 \%$ as a comparison to the base fluid. On the other hand, at $50^{\circ} \mathrm{C}$ and a volume concentration of $0.1 \%$, the pressure drop is increased by $16.9 \%$ at a Reynolds number of 5000. The increase in the alumina nanoparticle volume 


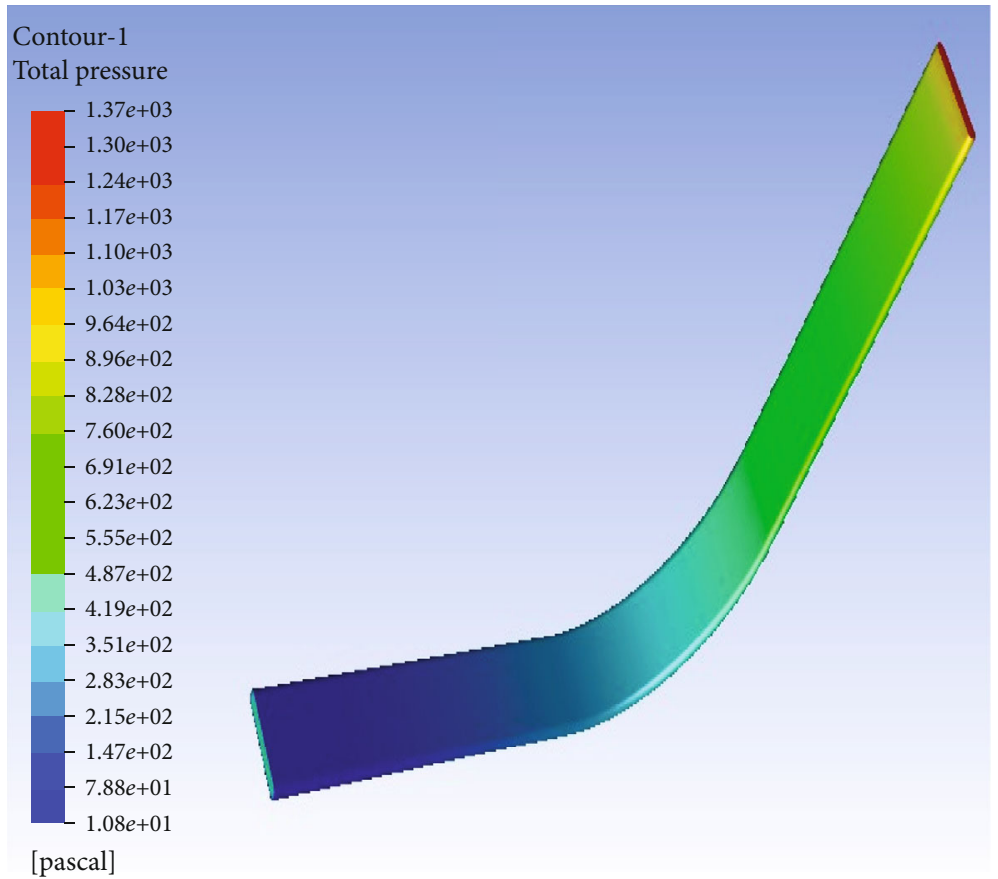

(a)

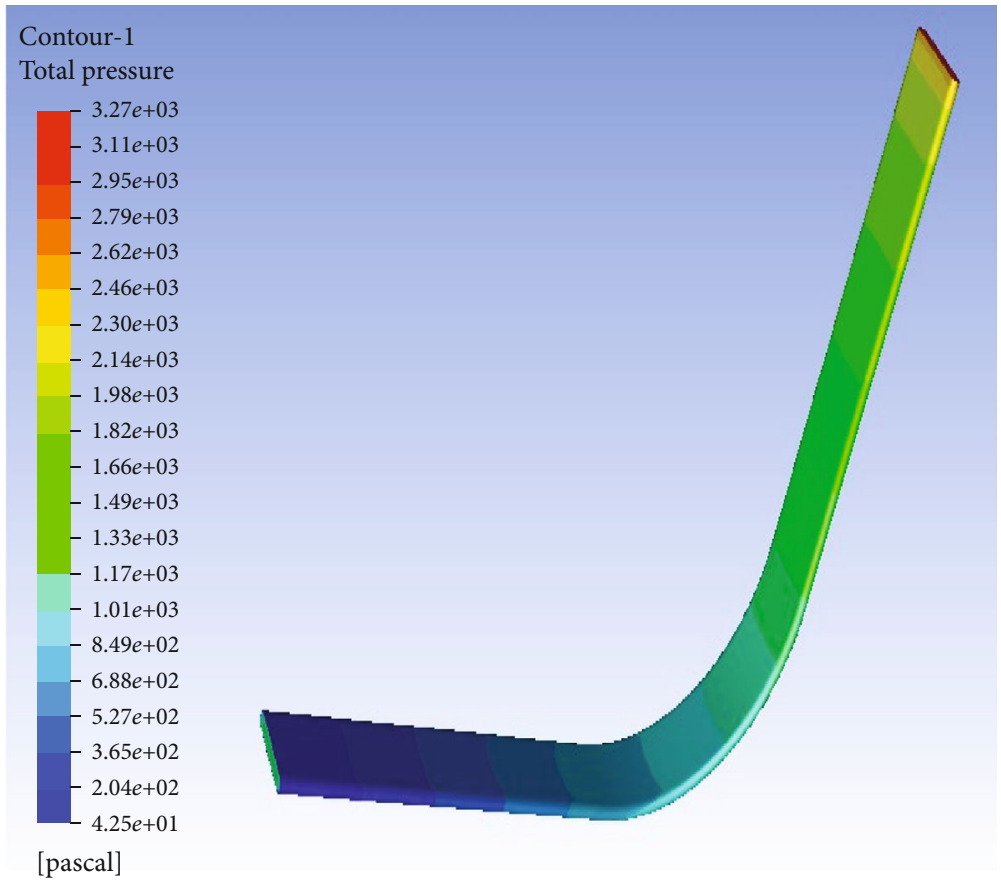

(b)

Figure 18: Pressure contours at various temperatures ( $T$ ) and Reynolds number (Re): (a) $T=40^{\circ} \mathrm{C}$ and $\mathrm{Re}=6000$; (b) $T=50^{\circ} \mathrm{C}$ and $\operatorname{Re}=11000$.

concentration from $0.1 \%$ to $0.5 \%$ at a constant Reynolds number of 5000 caused the pressure drop to decrease by $58 \%$. It can be seen that the pressure drop increased from $980 \mathrm{~Pa}$ to $1765 \mathrm{~Pa}$ at a Reynolds number of 7000 and fluid inlet temperature of $35^{\circ} \mathrm{C}$ when the alumina volume concentration is varied from 0 to $0.5 \%$. The maximum pressure drop of $3871 \mathrm{~Pa}$ is obtained at $35^{\circ} \mathrm{C}$ and a Reynolds number of 11000 . The pressure drop obtained in the case of $\mathrm{CuO}$ and carbon nanotubes is lower as compared with alumina nanoparticles. In the case of $\mathrm{CuO}$, the nanofluid maximum pressure drop of $2928 \mathrm{~Pa}$ is obtained at a fluid inlet temperature of $35^{\circ} \mathrm{C}$ and a volume concentration of $0.5 \%$ under a Reynolds number of 11000 . The minimum pressure drop of $403 \mathrm{~Pa}$ is obtained at fluid inlet temperature of $50^{\circ} \mathrm{C}$ and volume concentration of $0.1 \%$ under a Reynolds number of 5000. At a Reynolds number of 11000 , the increase in the 


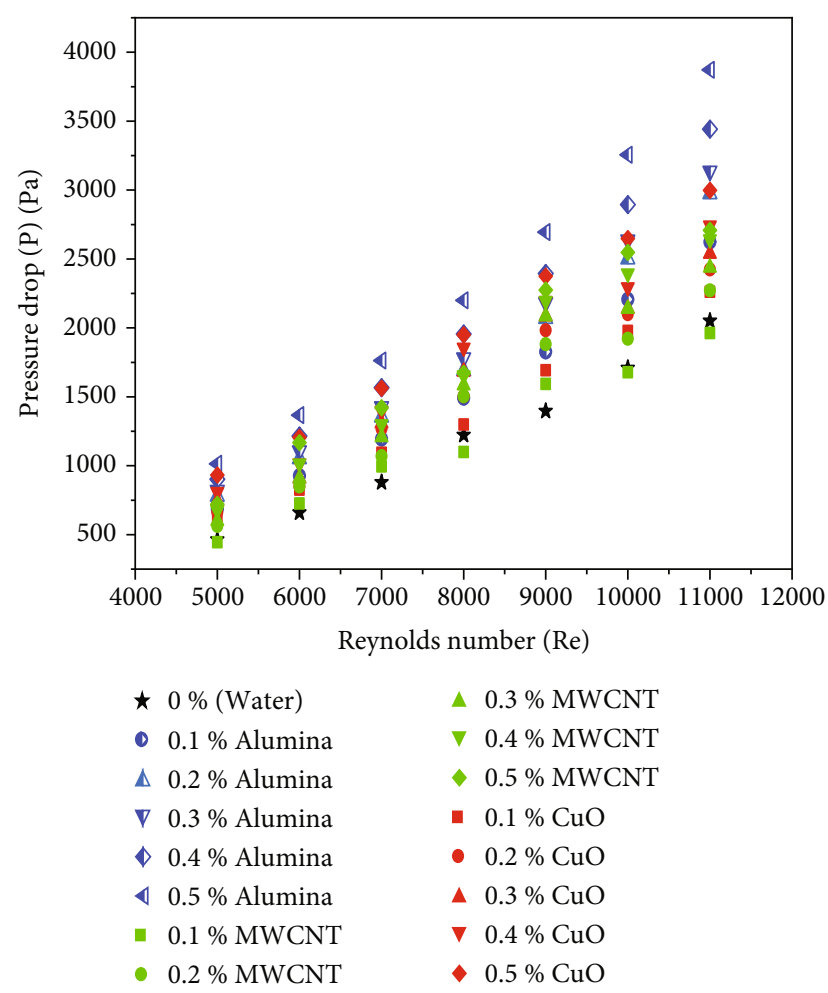

FIgURE 19: Variation in the pressure drop at $35^{\circ} \mathrm{C}$.

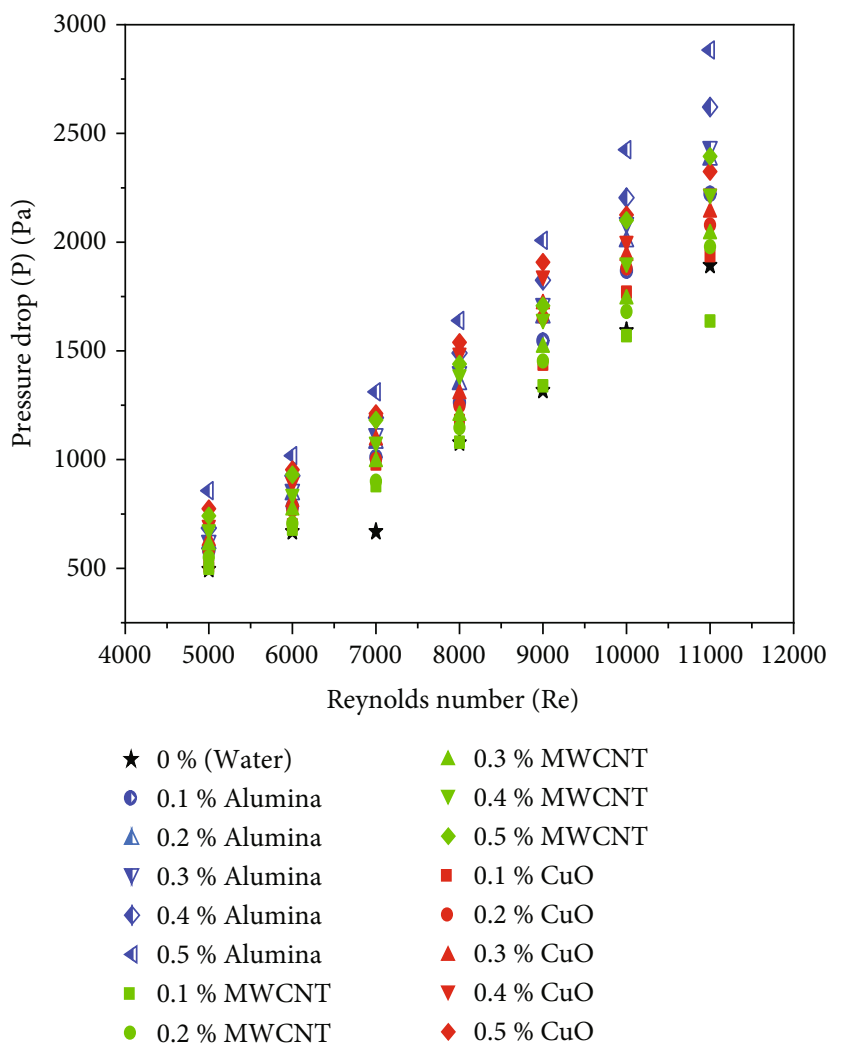

Figure 20: Variation in the pressure drop at $40^{\circ} \mathrm{C}$.

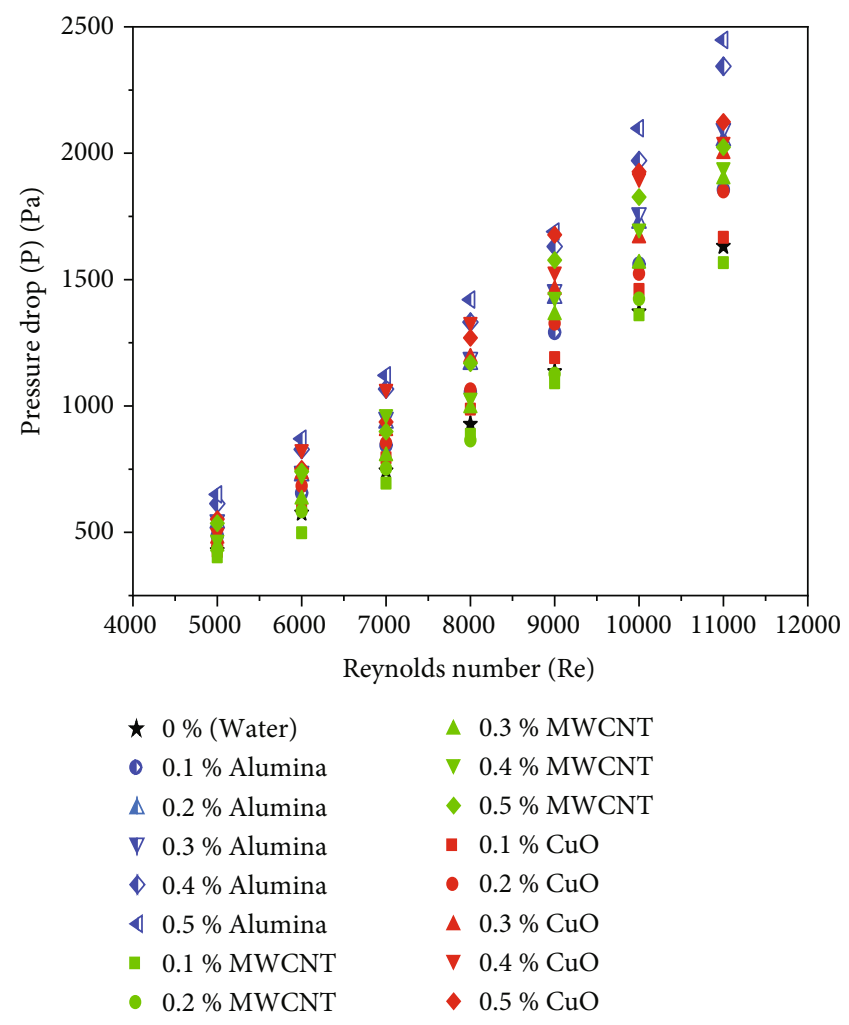

Figure 21: Variation in the pressure drop at $45^{\circ} \mathrm{C}$.

pressure drop is between 10 and $46 \%$ when volume concentration of $\mathrm{CuO}$ is varied between 0.1 and $0.5 \%$. Upon the use of carbon nanotubes, the maximum pressure drop of $2708 \mathrm{~Pa}$ is obtained at a fluid inlet temperature of $35^{\circ} \mathrm{C}$ and volume concentration of $0.5 \%$ at a Reynolds number of 11000. The minimum pressure drop of $351 \mathrm{~Pa}$ is obtained at a fluid inlet temperature of $50^{\circ} \mathrm{C}$ and volume concentration of $0.1 \%$ at a Reynolds number of 5000 . At a Reynolds number of 11000 , the increase in the pressure drop is between 10 and 32\% when the volume concentration of the carbon nanotube is varied between 0.1 and $0.5 \%$. The rising trend in the pressure drop with the increase in concentration is attributed to the fact that the viscosity of nanofluid is increased upon the addition of a higher quantity of nanoparticles to the base fluid. On the other hand, the pressure drop is decreased with the increasing of the volume concentration due to the decrease in viscosity and density due to the rise in the fluid temperature. The higher Brownian motion of particles at a higher temperature also causes the decrease of the pressure drop as suggested by Saxena et al. [63] and Zhao et al. [64].

As it is shown in Figure 24, the friction factor is decreased by increasing the Reynolds number and the alumina, $\mathrm{CuO}$, and carbon nanotube volume concentration. Variations in the friction factor for alumina nanofluid are presented in Figure 24. The obtained values of the friction factor was validated by using Moody's chart. The relative roughness was calculated by using respective correlation and found to be around 0.003738 . The results of the friction factor for water are closest to the Moody's results, and then, 


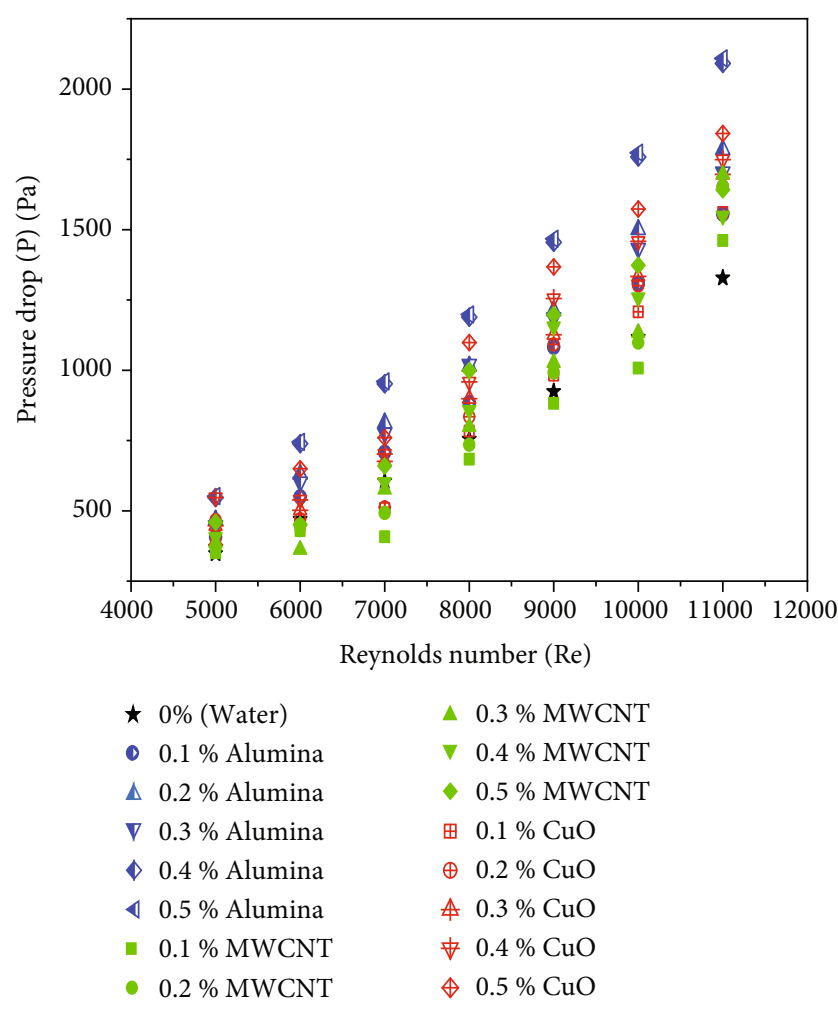

Figure 22: Variation in the pressure drop at $50^{\circ} \mathrm{C}$.

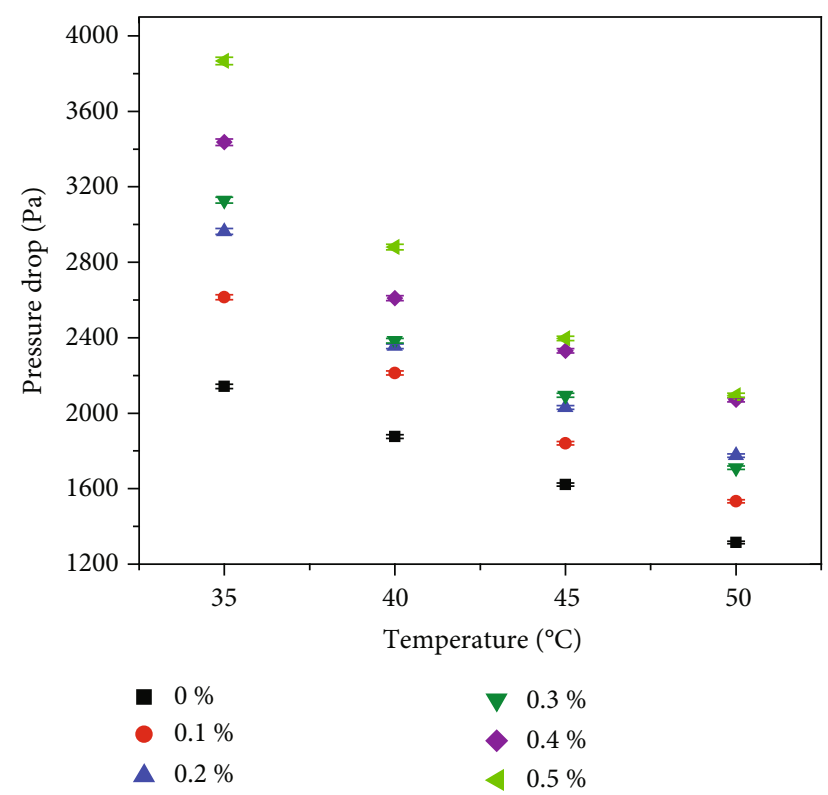

FIGURE 23: Variation in the pressure drop with respect to the temperature at a Reynolds number of 11000 .

the addition of nanoparticles into the base fluid increased the friction factor. Deviation in the friction factor upon the addition of the nanoparticle is found to be decreasing with increasing the Reynolds number. The maximum friction factor of 0.04532 is obtained at $0.5 \%$ volume concentration at $45^{\circ} \mathrm{C}$. While basic trends for all the nanoparticles used in this

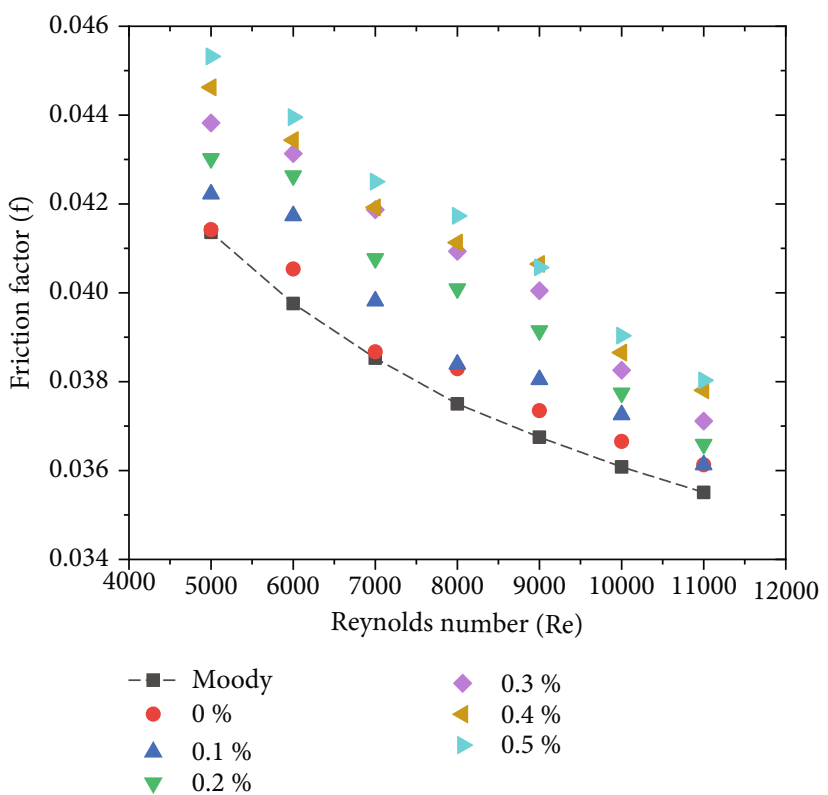

FIGURE 24: Variation in the friction factor.

study remain the same, it was observed that $\mathrm{CuO}$ nanofluids have a higher friction factor as compared with alumina and carbon nanotubes. Nanofluid with a carbon nanotube has the lowest friction factor amongst the three. The friction factor is decreased slightly with the increasing of the temperature due to the decrease in the density and viscosity of the nanofluid as a result of increasing the temperature. Therefore, the main reason for increasing the friction factor due to the nanoparticle addition is the increase in viscosity and density of nanofluid.

\section{Conclusion}

In this study, the effects of alumina, $\mathrm{CuO}$, and multiwalled carbon nanotube nanofluids flowing through the flat tube with a $90^{\circ}$ bend under volume concentrations of $0.1 \%$ to $0.5 \%$ have been numerically investigated. The numerical results are obtained by using a wide range of Reynolds number from 5000 to 11000 under different fluid inlet temperatures from $35^{\circ} \mathrm{C}$ to $50^{\circ} \mathrm{C}$. Numerical analysis was conducted with the help of the finite volume method. The second-order upwind method is used throughout this study for numerical analysis while keeping the residual setting for the convergence of the solution at $10^{-6}$. Based on the outcomes of this study, it can be concluded that the MWCNT/water nanofluid provides better heat transfer performance than $\mathrm{CuO} /$ water and $\mathrm{Al}_{2} \mathrm{O}_{3} /-$ water due to the more dominant effect of thermal conductivity of MWCNT nanoparticles. Minimum enhancement in the performance of was found in the case of $\mathrm{Al}_{2} \mathrm{O}_{3}$ /water nanofluids. Generally, it is observed that the heat transfer coefficient and Nusselt number increased with the increase in the volume concentration and Reynolds number for each nanofluids. The heat transfer coefficient and Nusselt number are observed to decrease when the temperature is increased from $35^{\circ} \mathrm{C}$ to $50^{\circ} \mathrm{C}$. The general trend in the case 
of all the nanofluids shows that the pressure drop increases with the increase in the Reynolds number while it decreases with the increase in temperature. MWCNT/water nanofluid reported the least pressure drop while $\mathrm{Al}_{2} \mathrm{O}_{3}$ /water reported the maximum pressure drop compared with others. The effect of the bend on the performance of the flat tube is also clearly presented in Figure 3 which clearly shows improvement in the performance of the tube. It can be seen that the enhancement in heat transfer through the tube is higher when a higher Reynolds number is used.

Some of the major findings of this study are summarized as follows:

(1) The heat transfer increases with alumina, $\mathrm{CuO}$, and carbon nanotube concentrations as well as the Reynolds number. In the case of alumina nanofluid, a maximum $19 \%$ increase in heat transfer coefficient compared with the base fluid is noted at the volume concentration of $0.5 \%$ and a Reynolds number of 11000. It was observed that the heat transfer coefficient for alumina nanofluid varies between $5500 \mathrm{~W} / \mathrm{m}^{2} \mathrm{~K}$ and $14000 \mathrm{~W} / \mathrm{m}^{2} \mathrm{~K}$ upon variation of the fluid inlet temperature from $35^{\circ} \mathrm{C}$ to $50^{\circ} \mathrm{C}$

(2) The heat transfer coefficient decreases with the increasing of inlet fluid temperature from $35^{\circ} \mathrm{C}$ to $50^{\circ} \mathrm{C}$. The Nusselt number is proportional to both the volume concentration and the Reynolds number and observed to decrease with the decrease in the inlet fluid temperature. The maximum increase of $15 \%, 44 \%$, and $52 \%$ in the Nusselt number from base fluid is obtained at a $0.5 \%$ volume concentration for alumina, $\mathrm{CuO}$, and carbon nanotubes, respectively

(3) The pressure drop in the tube increases with the increase in volume concentration and Reynolds number. Besides, a significant decrease in the pressure drop is achieved when the temperature increases from $35^{\circ} \mathrm{C}$ to $50^{\circ} \mathrm{C}$

(4) The maximum pressure drop of $3871 \mathrm{~Pa}$ is obtained at $35^{\circ} \mathrm{C}$ and volume concentration of $0.5 \%$ at a Reynolds number of 11000 , while the minimum pressure drop of $406 \mathrm{~Pa}$ is obtained at inlet fluid temperature of $50^{\circ} \mathrm{C}$ and volume concentration of $0.1 \%$ at a Reynolds number of 5000. The maximum pressures drop in $\mathrm{CuO}$ and carbon nanotubes are $2928 \mathrm{~Pa}$ and $2708 \mathrm{~Pa}$, respectively, at a volume concentration of $0.5 \%$ and a Reynolds number of 11000 . The pressure drop for alumina nanofluid is higher as compared with $\mathrm{CuO}$ and carbon nanotubes

(5) Using the $\mathrm{Al}_{2} \mathrm{O}_{3}, \mathrm{CuO}$, and carbon nanotube, the volume concentration increases the friction factor. Also, increasing the Reynolds number decreases the friction factor. $\mathrm{CuO}$ nanofluids have a higher friction factor as compared with alumina and carbon nanotubes. $\mathrm{CuO}$ and carbon nanotubes were found to have a better heat transfer and fluid flow performance as compared with alumina nanofluid
(6) The heat transfer performance of nanoparticles flowing through the flat tube with a designed bend is fully capable of improving the heat transfer performance in comparison to base fluid and also could reduce the size of the device for achieving the same output. The Nusselt number of fluid flow through the bend is enhanced by $8 \%$ from the flat tube without the bend. On the other hand, the use of the nanoparticle will also require a higher pumping power for operations due to the increased pressure drop

\section{Future Scopes}

This work focused on the performance of three nanofluids, i.e., $\mathrm{CuO} /$ water, $\mathrm{Al}_{2} \mathrm{O}_{3}$ /water, and $\mathrm{MWCNT} /$ water through a flat tube bent by $90^{\circ}$ at a fluid inlet temperature ranging from $35^{\circ} \mathrm{C}$ to $50^{\circ} \mathrm{C}$. The current investigation implies that MWCNT/water provides better heat transfer performance than $\mathrm{CuO}$ /water and $\mathrm{Al}_{2} \mathrm{O}_{3}$ /water. $\mathrm{Al}_{2} \mathrm{O}_{3}$ /water was found to provide the least performance among the three. More studies are required to completely understand and validate the behavior of these nanofluids under the influence of bends. Different nanofluids like $\mathrm{SiO}_{2}, \mathrm{TiO}_{2}, \mathrm{Fe}_{3} \mathrm{O}_{4}$, and $\mathrm{ZnO}$ can be used as nanofluids to study the behavior of these nanofluids through the current system. Further investigation can be carried out at a higher Reynolds number and the temperature ranges beyond $50^{\circ} \mathrm{C}$. The angle of the bend can also be varied to understand its effect on the performance of the tube. Configuration of the tube considered in this study was flat while the scope of this type of study can be extended to different configurations, i.e., elliptical tube, rectangular tube, and circular tube.

\section{Nomenclature}

$C_{p}:$ Specific heat capacity $(\mathrm{J} / \mathrm{kg} \cdot \mathrm{K})$

$D_{h}$ : Hydraulic diameter of the tube $(\mathrm{m})$

$d_{p}:$ Nanoparticle diameter $(\mathrm{nm})$

$f:$ Friction factor

$h$ : Heat transfer coefficient $\left(\mathrm{W} / \mathrm{m}^{2} \cdot \mathrm{K}\right)$

$K: \quad$ Thermal conductivity $(\mathrm{W} / \mathrm{m} \cdot \mathrm{K})$

$K_{e}: \quad$ Effective thermal conductivity $(\mathrm{W} / \mathrm{m} \cdot \mathrm{K})$

$K_{p}$ : Particle thermal conductivity $(\mathrm{W} / \mathrm{m} \cdot \mathrm{K})$

Nu: Nusselt number

$P: \quad$ Pressure $(\mathrm{Pa})$

Re: Reynolds number

$T: \quad$ Temperature (K)

$V:$ Average velocity $(\mathrm{m} / \mathrm{s})$

$V_{p}$ : Particle volume equation

$n: \quad$ Nanoparticle volume fraction (\%)

$\psi$ : Particle sphericity

$\phi$ : $\quad$ Shape factor

$\rho: \quad$ Density $\left(\mathrm{kg} / \mathrm{m}^{3}\right)$

$\mu$ : Viscosity $(\mathrm{kg} / \mathrm{m} \cdot \mathrm{s})$

${ }_{b}$ : Bulk mean

bf: Base fluid

$f$ : Fluid

${ }_{\mathrm{nf}}$ : Nanofluid 
$\begin{array}{ll}{ }_{n p}: & \text { Nanoparticle } \\ p & \text { Particle. }\end{array}$

\section{Data Availability}

The data used to support the findings of this study are included within the article.

\section{Conflicts of Interest}

The authors declare no conflict of interest.

\section{References}

[1] H. Maddah, M. Alhuyi Nazari, G. Lorenzini, M. Fahim Alavi, R. Ghasempour, and M. H. Sharifpur, "Modeling thermal conductivity ratio of $\mathrm{CuO} /$ ethylene glycol nanofluid by using artificial neural network," Defect and Diffusion Forum, vol. 388, pp. 39-43, 2018.

[2] S. M. Fotukian and M. Nasr Esfahany, "Experimental investigation of turbulent convective heat transfer of dilute $\gamma-\mathrm{Al}_{2} \mathrm{O}_{3} /$ water nanofluid inside a circular tube," International Journal of Heat and Fluid Flow, vol. 31, no. 4, pp. 606-612, 2010.

[3] H. Safikhani and A. Abbassi, "Effects of tube flattening on the fluid dynamic and heat transfer performance of nanofluids," Advanced Powder Technology, vol. 25, no. 3, pp. 1132-1141, 2014.

[4] R. Jilte, M. H. Ahmadi, R. Kumar, V. Kalamkar, and A. Mosavi, "Cooling performance of a novel circulatory flow concentric multi-channel heat sink with nanofluids," Nanomaterials, vol. 10, no. 4, p. 647, 2020.

[5] K. Cacua, S. M. S. Murshed, E. Pabón, and R. Buitrago, "Dispersion and thermal conductivity of $\mathrm{TiO}_{2}$ /water nanofluid," Journal of Thermal Analysis and Calorimetry, vol. 140, no. 1, pp. 109-114, 2020.

[6] M. H. Ahmadi, M. Ghazvini, M. Sadeghzadeh, M. Alhuyi Nazari, and M. Ghalandari, "Utilization of hybrid nanofluids in solar energy applications: a review," Nano-Structures \& Nano-Objects, vol. 20, article 100386, 2019.

[7] H. Maddah, M. Ghazvini, and M. H. Ahmadi, "Predicting the efficiency of $\mathrm{CuO} /$ water nanofluid in heat pipe heat exchanger using neural network," International Communications in Heat and Mass Transfer, vol. 104, pp. 33-40, 2019.

[8] M. H. Ahmadi, M. Ghazvini, M. Alhuyi Nazari et al., "Renewable energy harvesting with the application of nanotechnology: a review," International Journal of Energy Research, vol. 43, no. 4, pp. 1387-1410, 2019.

[9] M. H. Ahmadi, B. Mohseni-Gharyehsafa, M. Ghazvini, M. Goodarzi, R. D. Jilte, and R. Kumar, "Comparing various machine learning approaches in modeling the dynamic viscosity of $\mathrm{CuO}$ /water nanofluid," Journal of Thermal Analysis and Calorimetry, vol. 139, no. 4, pp. 2585-2599, 2020.

[10] M. Ramezanizadeh, M. Alhuyi Nazari, M. H. Ahmadi, and E. Açıkkalp, "Application of nanofluids in thermosyphons: a review," Journal of Molecular Liquids, vol. 272, pp. 395-402, 2018.

[11] R. R. Sahoo and V. Kumar, "Development of a new correlation to determine the viscosity of ternary hybrid nanofluid," International Communications in Heat and Mass Transfer, vol. 111, article 104451, 2020.
[12] A. Abdollahi, M. H. Karimi Darvanjooghi, A. Karimipour, and M. R. Safaei, "Experimental study to obtain the viscosity of CuO-loaded nanofluid: effects of nanoparticles' mass fraction, temperature and basefluid's types to develop a correlation," Meccanica, vol. 53, no. 15, pp. 3739-3757, 2018.

[13] S. M. S. Murshed, F. J. V. Santos, C. A. Nieto de Castro, V. S. Patil, and K. R. Patil, "Morphology and thermophysical properties of non-aqueous titania nanofluids," Heat and Mass Transfer, vol. 54, no. 9, pp. 2645-2650, 2018.

[14] A. Nikulin, A. S. Moita, A. L. N. Moreira et al., "Effect of $\mathrm{Al}_{2} \mathrm{O}_{3}$ nanoparticles on laminar, transient and turbulent flow of isopropyl alcohol," International Journal of Heat and Mass Transfer, vol. 130, pp. 1032-1044, 2019.

[15] W. Duangthongsuk and S. Wongwises, "Measurement of temperature-dependent thermal conductivity and viscosity of $\mathrm{TiO}_{2}$-water nanofluids," Experimental Thermal and Fluid Science, vol. 33, no. 4, pp. 706-714, 2009.

[16] R. S. Khedkar, S. S. Sonawane, and K. L. Wasewar, "Influence of $\mathrm{CuO}$ nanoparticles in enhancing the thermal conductivity of water and monoethylene glycol based nanofluids," International Communications in Heat and Mass Transfer, vol. 39, no. 5, pp. 665-669, 2012.

[17] L. Godson, B. Raja, D. M. Lal, and S. Wongwises, "Experimental investigation on the thermal conductivity and viscosity of silver-deionized water nanofluid," Jacob Bauman, vol. 23, no. 4, pp. 317-332, 2010.

[18] C. Sitprasert, Æ. P. Dechaumphai, and V. Juntasaro, “A thermal conductivity model for nanofluids including effect of the temperature-dependent interfacial layer," Journal of Nanoparticle Research, vol. 11, no. 6, pp. 1465-1476, 2009.

[19] M. Beck, Y. Yuan, P. Warrier, and A. Teja, "The thermal conductivity of alumina nanofluids in water, ethylene glycol, and ethylene glycol + water mixtures," Journal of Nanoparticle Research, vol. 12, pp. 1469-1477, 2009.

[20] O. Khliyeva, V. Zhelezny, T. Lukianova et al., "A new approach for predicting the pool boiling heat transfer coefficient of refrigerant R141b and its mixtures with surfactant and nanoparticles using experimental data," Journal of Thermal Analysis and Calorimetry, vol. 142, no. 6, pp. 2327-2339, 2020.

[21] B. Mosavati, M. Mosavati, and F. Kowsary, "Inverse boundary design solution in a combined radiating-free convecting furnace filled with participating medium containing specularly reflecting walls," International Communications in Heat and Mass Transfer, vol. 76, pp. 69-76, 2016.

[22] B. Mosavati, M. Mosavati, and F. Kowsary, "Solution of radiative inverse boundary design problem in a combined radiating- free convecting furnace," International Communications in Heat and Mass Transfer, vol. 45, pp. 130-136, 2013.

[23] M. Mosavati, F. Kowsary, and B. Mosavati, "A novel, Noniterative inverse boundary design regularized solution Technique using the backward Monte Carlo method," Journal of Heat Transfer, vol. 135, no. 4, 2013.

[24] M. R. Safaei, O. Mahian, F. Garoosi et al., "Investigation of Micro- and Nanosized Particle Erosion in a $90^{\circ}$ Pipe Bend Using a Two-Phase Discrete Phase Model," The Scientific World Journal, vol. 2014, Article ID 740578, 12 pages, 2014.

[25] M. Chandrasekar, S. Suresh, and A. Chandra Bose, "Experimental studies on heat transfer and friction factor characteristics of $\mathrm{Al}_{2} \mathrm{O}_{3}$ /water nanofluid in a circular pipe under laminar flow with wire coil inserts," Experimental Thermal and Fluid Science, vol. 34, no. 2, pp. 122-130, 2010. 
[26] E. Jalali, O. Ali Akbari, M. M. Sarafraz, T. Abbas, and M. R. Safaei, "Heat transfer of oil/MWCNT nanofluid jet injection inside a rectangular microchannel," Symmetry, vol. 11, no. 6, p. $757,2019$.

[27] H. A. Mintsa, G. Roy, C. T. Nguyen, and D. Doucet, "New temperature dependent thermal conductivity data for water-based nanofluids," International Journal of Thermal Sciences, vol. 48, no. 2, pp. 363-371, 2009.

[28] A. A. Abbasian Arani and J. Amani, "Experimental investigation of diameter effect on heat transfer performance and pressure drop of $\mathrm{TiO}_{2}$-water nanofluid," Experimental Thermal and Fluid Science, vol. 44, pp. 520-533, 2013.

[29] S. Z. Heris, A. K. Beydokhti, S. H. Noie, and S. Rezvan, "Engineering applications of computational fluid mechanics numerical study on convective heat transfer of $\mathrm{AL}_{2} \mathrm{O}_{3} /$ water , $\mathrm{CuO} /$ water and $\mathrm{Cu} /$ water nanofluids through square crosssection duct in laminar flow," Engineering Applications of Computational Fluid Mechanics, vol. 6, pp. 1-14, 2012.

[30] I. Gherasim, G. Roy, C. T. Nguyen, and D. Vo-Ngoc, "Experimental investigation of nanofluids in confined laminar radial flows," International Journal of Thermal Sciences, vol. 48, no. 8, pp. 1486-1493, 2009.

[31] L. Kolsi, F. Selimefendigil, H. F. Öztop, W. Hassen, and W. Aich, "Impacts of double rotating cylinders on the forced convection of hybrid nanofluid in a bifurcating channel with partly porous layers," Case Studies in Thermal Engineering, vol. 26, p. 101020, 2021.

[32] A. Malvandi, M. R. Safaei, M. H. Kaffash, and D. D. Ganji, "MHD mixed convection in a vertical annulus filled with $\mathrm{Al}_{2} \mathrm{O}_{3}$-water nanofluid considering nanoparticle migration," Journal of Magnetism and Magnetic Materials, vol. 382, pp. 296-306, 2015.

[33] S. O. Giwa, M. Sharifpur, and J. P. Meyer, "Experimental study of thermo-convection performance of hybrid nanofluids of $\mathrm{Al}_{2} \mathrm{O}_{3}$-MWCNT/water in a differentially heated square cavity," International Journal of Heat and Mass Transfer, vol. 148, article 119072, 2020.

[34] S. O. Giwa, M. Sharifpur, and J. P. Meyer, "Effects of uniform magnetic induction on heat transfer performance of aqueous hybrid ferrofluid in a rectangular cavity," Applied Thermal Engineering, vol. 170, article 115004, 2020.

[35] D. Madhesh and S. Kalaiselvam, "Experimental analysis of hybrid nanofluid as a coolant," Procedia Engineering, vol. 97, pp. 1667-1675, 2014.

[36] M. H. Ahmadi, M. Ghazvini, H. Maddah et al., "Prediction of the pressure drop for $\mathrm{CuO} /($ ethylene glycol-water) nanofluid flows in the car radiator by means of artificial neural networks analysis integrated with genetic algorithm," Physica A: Statistical Mechanics and its Applications, vol. 546, article 124008, 2020.

[37] S. O. Giwa, M. Sharifpur, M. Goodarzi, H. Alsulami, and J. P. Meyer, "Influence of base fluid, temperature, and concentration on the thermophysical properties of hybrid nanofluids of alumina-ferrofluid: experimental data, modeling through enhanced ANN, ANFIS, and curve fitting," Journal of Thermal Analysis and Calorimetry, vol. 143, no. 6, pp. 4149-4167, 2020.

[38] S. Aghakhani, A. H. Pordanjani, M. Afrand, M. Sharifpur, and J. P. Meyer, "Natural convective heat transfer and entropy generation of alumina/water nanofluid in a tilted enclosure with an elliptic constant temperature: applying magnetic field and radiation effects," International Journal of Mechanical Sciences, vol. 174, article 105470, 2020.
[39] M. Elsebay, I. Elbadawy, M. H. Shedid, and M. Fatouh, "Numerical resizing study of $\mathrm{Al}_{2} \mathrm{O}_{3}$ and $\mathrm{CuO}$ nanofluids in the flat tubes of a radiator," Applied Mathematical Modelling, vol. 40, no. 13-14, pp. 6437-6450, 2016.

[40] T. Perrotin and D. Clodic, "Analyse, par dynamique des fluides numerisee, des proprietes thermohydrauliques des echangeurs de chaleur a tubes plats et persiennes," International Journal of Refrigeration, vol. 27, no. 4, pp. 422-432, 2004.

[41] O. Hamed, M. Torabi, M. Bahiraei, M. H. Ahmadi, M. Goodarzi, and M. R. Safaei, "Application of nanofluids in thermal performance enhancement of parabolic trough solar collector: state-of-the-art," Applied Sciences, vol. 9, no. 3, p. 463, 2019.

[42] M. Sadeghzadeh, H. Maddah, M. H. Ahmadi et al., "Prediction of thermo-physical properties of $\mathrm{TiO} 2-\mathrm{Al} 2 \mathrm{O} 3 /$ Water nanoparticles by using artificial neural network," Nanomaterials, vol. 10, no. 4, p. 697, 2020.

[43] R. S. Matos, T. A. Laursen, J. V. C. Vargas, and A. Bejan, "Three-dimensional optimization of staggered finned circular and elliptic tubes in forced convection," International Journal of Thermal Sciences, vol. 43, pp. 477-487, 2004.

[44] V. Bianco, O. Manca, and S. Nardini, "Numerical investigation on nanofluids turbulent convection heat transfer inside a circular tube," International Journal of Thermal Sciences, vol. 50, no. 3, pp. 341-349, 2011.

[45] R. Siegel, E. M. Sparrow, and T. M. Hallman, "Steady laminar heat transfer in a circular tube with prescribed wall heat flux," Applied Scientific Research, Section A, vol. 7, no. 5, pp. 386392, 1958.

[46] L. Sun and C. Zhang, "Evaluation of elliptical finned-tube heat exchanger performance using CFD and response surface methodology," International Journal of Thermal Sciences, vol. 75, pp. 45-53, 2014.

[47] I. Gherasim, N. Galanis, and C. T. Nguyen, "Numerical study of nanofluid flow and heat transfer in a plate heat exchanger," Computational Thermal Sciences: An International Journal, vol. 5, no. 4, pp. 317-332, 2013.

[48] O. A. Akbari, D. Toghraie, A. Karimipour et al., "Investigation of rib's height effect on heat transfer and flow parameters of laminar water- $\mathrm{Al}_{2} \mathrm{O}_{3}$ nanofluid in a rib-microchannel," Applied Mathematics and Computation, vol. 290, pp. 135153, 2016.

[49] Y. He, Y. Jin, H. Chen, Y. Ding, D. Cang, and H. Lu, "Heat transfer and flow behaviour of aqueous suspensions of $\mathrm{TiO}_{2}$ nanoparticles (nanofluids) flowing upward through a vertical pipe," International Journal of Heat and Mass Transfer, vol. 50, no. 11-12, pp. 2272-2281, 2007.

[50] M. Kahani, S. Zeinali Heris, and S. M. Mousavi, "Comparative study between metal oxide nanopowders on thermal characteristics of nanofluid flow through helical coils," Powder Technology, vol. 246, pp. 82-92, 2013.

[51] D. Kumar and G. S. Sokhal, "Numerical analysis of performance of water-based nanofluid flowing through tube bent at 90', Heat Transfer-Asian Research, vol. 49, no. 1, pp. 18 32, 2020.

[52] P. Sharma, V. Kumar, G. S. Sokhal, G. Dasaroju, and V. K. Bulasara, "Numerical study on performance of flat tube with water based copper oxide nanofluids," Materials Today: Proceedings, vol. 21, pp. 1800-1808, 2020.

[53] G. S. Sokhal, D. Gangacharyulu, and V. K. Bulasara, "Heat transfer and pressure drop performance of alumina-water 
nanofluid in a flat vertical tube of a radiator," Chemical Engineering Communications, vol. 205, no. 2, pp. 257-268, 2018.

[54] F. Selimefendigil and H. F. Öztop, "Hydro-thermal performance of CNT nanofluid in double backward facing step with rotating tube bundle under magnetic field," International Journal of Mechanical Sciences, vol. 185, article 105876, 2020.

[55] R. L. Hamilton and O. K. Crosser, "Thermal conductivity of heterogeneous Two-Component systems," Industrial \& Engineering Chemistry Fundamentals, vol. 1, no. 3, pp. 187-191, 1962.

[56] B. C. Pak and Y. I. Cho, "Hydrodynamic and heat transfer study of dispersed fluids with submicron metallic oxide particles," Experimental Heat Transfer an International Journal, vol. 11, pp. 151-170, 1998.

[57] H. C. Brinkman, "The viscosity of concentrated suspensions and solutions," The Journal of Chemical Physics, vol. 20, p. $571,1952$.

[58] Y. Xuan and W. Roetzel, "Conceptions for heat transfer correlation of nanofluids," International Journal of heat and Mass transfer, vol. 43, pp. 3701-3707, 2000.

[59] G. S. Sokhal, D. Gangacharyulu, and V. K. Bulasara, "Influence of copper oxide nanoparticles on the thermophysical properties and performance of flat tube of vehicle cooling system.," Vacuum, vol. 157, pp. 268-276, 2018.

[60] H. Chen, W. Yang, Y. He et al., "Heat transfer and flow behaviour of aqueous suspensions of titanate nanotubes (nanofluids)," Powder Technology, vol. 183, pp. 63-72, 2008.

[61] D. Wen and Y. Ding, "Experimental investigation into convective heat transfer of nanofluids at the entrance region under laminar flow conditions," International Journal of Heat and Mass Transfer, vol. 47, pp. 5181-5188, 2004.

[62] M. Naraki, S. M. Peyghambarzadeh, S. H. Hashemabadi, and Y. Vermahmoudi, "Parametric study of overall heat transfer coefficient of $\mathrm{CuO}$ /water nanofluids in a car radiator," International Journal of Thermal Sciences, vol. 66, pp. 82-90, 2013.

[63] R. Saxena, D. Gangacharyulu, and V. K. Bulasara, "Heat transfer and pressure drop characteristics of dilute alumina-water nanofluids in a pipe at different power inputs," Heat Transfer Engineering, vol. 7632, 2016.

[64] N. Zhao, J. Yang, H. Li, Z. Zhang, and S. Li, "Numerical investigations of laminar heat transfer and flow performance of $\mathrm{Al}_{2} \mathrm{O}_{3}$-water nanofluids in a flat tube," International Journal of Heat and Mass Transfer, vol. 92, pp. 268-282, 2016. 